\title{
SUBJECTIVACIÓ I EVIDENCIALITAT: EL VERB AMENAÇAR FINS AL SEGLE XIX. UN ESTUDI DE CORPUS ${ }^{1}$
}

\author{
JORDI M. ANTOLÍ MARTÍNEZ \\ Universitat d'Alacant \\ jordi.antoli@gcloud.ua.es \\ ORCID: 0000-0003-2273-653X
}

RESUM

En català actual, el verb amenaçar coneix, juntament amb un valor lèxic (amb subjecte agent), un valor d'auxiliar evidencial (segons la definició de Cornillie 2016) que permet realitzacions com: amenaçava de ploure (DIEC2, s.v. amenaçar, 3; DDLC, s.v. amenaçar, 5). El desplegament d'aquest valor ha estat explicat, per al cas de l'anglès (com a epistèmic: Traugott 1997) i de l'espanyol (Cornillie 2007, 2016; Cornillie i Octavio de Toledo 2015), amb el concepte de subjectivació (d'acord amb la proposta de Traugott i Dasher 2002). Seguint aquesta línia de recerca, en aquest estudi provem de descriure i explicar el procés de canvi pel qual aquest verb desenvoluparà, en català, el valor epistèmic/evidencial durant l'època moderna, en un procés que culminarà ja en el segle XIX. La recerca es fonamentarà en el buidatge $i$ anàlisi de dades de corpus textuals informatitzats del català antic, modern i contemporani. Les dades obtingudes seran analitzades qualitativament i quantitativa, i interpretades mitjançant les eines teòriques de què ens forneix la Lingüística Cognitiva i la Gramàtica de Construccions basada en l'ús d'acord amb la proposta de Traugott i Trousdale (2013) i la Invited Inferencing Theory of Semantic Change (IITSC) de Traugott (2012).

MOTS CLAU: català modern i contemporani, corpus textual informatitzat, evidencialitat, inferència invitada, Lingüística Diacrònica, subjectivació.

\section{SUBJECTIVATION AND EVIDENTIALITY: THE VERB AMENAÇAR UNTIL THE $1^{\mathrm{TH}}$ CENTURY. A CORPUS STUDY}

\section{ABSTRACT}

In current Catalan, the verb amenaçar possess, together with a lexical meaning (with agentive subject), an evidential auxiliary value (according to Cornillie 2016) that gives way to productions such as: amenaçava de ploure (DIEC2, s.v. amenaçar, 3; DDLC, s.v. amenaçar, 5). The unfolding of this value has been explained, in the case of English (as epistemic: Traugott 1997) and in Spanish (Cornillie 2007, 2016; Cornillie and Octavio de Toledo 2015) with the concept of

${ }_{1}$ Aquest estudi ha estat dut a terme en el marc de l'Institut Superior d'Investigació Cooperativa IVITRA [ISIC-IVITRA] (Ref. ISIC/012/042) i finançat pels projectes següents: Gestión de la Información y Estructuración Lingüística (GestInf), del Ministerio de Ciencia, Innovación y Universidades del Gobierno de España (FFI2017-85441-R); Variación y cambio lingüístico en catalán. Una aproximación diacrónica según la lingüística de corpus (VARIALINGCA) del Ministerio de Ciencia, Innovación y Universidades del Gobierno de España (FFI PGC2018099399-B-I00); projecte de recerca de l'Institut d'Estudis Catalans (Ref. PRO2018-S04MARTINES); del Grup d'Investigació VIGROB-125 de la UA; i Grup d'Investigació en Tecnologia Educativa en Història de la Cultura, Diacronia lingüística i Traducció (Universitat d'Alacant, Ref. GITE-09009-UA]). 
subjectivation (according to Traugott and Dasher 2002). Following this line of research, in this study we try to describe and explain the process of change, in which the aforementioned verb will develop, in Catalan, an epistemic/evidential value during the Early Modern period, in a process that will culminate in the $19^{\text {th }}$ century. The investigation will be based on the emptying and analysis of computerized textual corpus data of ancient, modern and contemporary Catalan. The data obtained will be analysed qualitatively and quantitatively, and interpreted using the theoretical tools that the Cognitive Linguistics and the Usage-Based Construction Grammar provides, according to Traugott and Trousdale (2013) and Traugott's Invited Inferencing Theory of Semantic Change (IITSC) (2012).

KEYWORDS: Modern and Contemporary Catalan, computerised textual corpus, evidentiality, invited inference, diachronic linguistics, subjectivation.

\section{INTRODUCCIÓ ${ }^{2}$}

El verb amenaçar, en català contemporani, presenta dos valors situats en dominis conceptuals diferents: d'una banda, el verb agentiu, que descriu un acte de parla pel qual el locutor expressa una amenaça (DDLC, s.v. amenaçar, 2a): 'Anunciar a [algú que està en disposició de fer o no fer una cosa] [un mal, un càstig] com a conseqüència'. I, en segon lloc, trobem un nucli semàntic més subjectiu, amb significats de caràcter epistèmic: '[Un perill, un mal]1 presentarse a [algú, alguna cosa]2 com a probable' (DDLC, s.v. amenaçar, 3); i epistèmic/evidencial: 'Donar senyals d'estar a punt d'ocórrer [un esdeveniment advers]' (DDLC, s.v. amenaçar, 5), en contextos com: El temps amenaça pluja. Aquests llampecs amenacen tempesta. Aquesta casa amenaça ruïna. Aquest matí amenaçava pluja, amenaçava de ploure (DIEC2, s.v. amenaçar, 3). Amb aquest darrer significat, el locutor (des d'aquest punt, L) expressa que la predicció enunciada s'infereix a partir d'uns indicis, i mostra alhora una actitud negativa envers l'esdeveniment previst. Aquesta funció pot qualificar-se d'evidencial, entenent per evidencialitat la categoria semàntica i funcional de caràcter universal que agrupa tots aquells recursos lingüístics que marquen en el discurs la font de la informació enunciada pel locutor. Aquesta interpretació del concepte d'evidencialitat ha estat desenvolupada especialment en els darrers anys per investigadors com Cornillie (2007, 2016), Squartini (2004, 2012) o Diewald i Smirnova (2010), en oposició a una interpretació més restrictiva del concepte que es refereix a una categoria gramatical obligatòria amb aquesta mateixa funció que és present solament en determinades llengües. En aquest estudi farem ús dels termes evidencialitat i evidencial d'acord amb aquesta interpretació més àmplia del concepte, en la línia que hem desenvolupat en alguns treballs anteriors (Antolí 2015a, 2015b i 2015c).

\footnotetext{
${ }^{2}$ Les abreviatures utilitzades en l'estudi són les següents: $A$ : agent; cat.: català; $L$ : locutor; $L / C$ : locutor/conceptualitzador; $N$ : substantiu; $S$ : subjecte; $S / A$ : subjecte agent; $V$ : verb; Vinf: verb infinitiu.
} 
En el context romànic, aquest no és un valor exclusiu del català (d'ara endavant, cat.), sinó que és general: el trobem en aragonés ('se aplica cuando alguna cosa deja prever un peligro'; Endize, s.v. amenasá), asturià (DALLA, s.v. amenazar, 3), espanyol (DMoliner, s.v. amenazar), francés (TLF, s.v. menacer, I.B.1, I.B.2, II.D, III; DAcadémie, s.v. menacer, 2), italià (VTreccani, s.v. minacciare, 2b) o en occità (DCantalausa, s.v. menaçar).

Quant a l'origen del valor epistèmic/evidencial, destaca l'interès que ha suscitat la qüestió especialment des d'un acostament cognitiu-funcional. L'evolució que descriu el verb i que dona lloc a un auxiliar evidencial, segons el qualifica Cornillie (2004, 2005, 2007, 2016), ha estat considerada un exemple paradigmàtic de gramaticalització, i s'ha explicat com a resultat d'un procés de subjectivació semàntica aparellat a la descategorització del verb. Val a dir que en aquest estudi seguim el concepte de subjectivació desplegat per E. C. Traugott en diversos treballs, entès com el:

semasiological process whereby SP/Ws come over time to develop meanings for Ls that encode or externalize their perspectives and attitudes as constrained by the communicative world of the speech event, rather than by the so-called 'real-world' characteristics of the event or situation referred to. (Traugott i Dasher 2002: 30)

Tot i que aquest procés gradual de canvi lingüístic està motivat semànticament, sol comportar també unes restriccions en el comportament sintàctic de l'expressió que Company (2004) sistematitza en: a) atenuació, debilitament o inclús pèrdua del control de l'agent sobre l'esdeveniment; $b$ ) ampliació de l'abast de la predicació; i c) fixació, ailllament i autonomia predicativa.

La primera a analitzar el procés de canvi dels equivalents de amenaçar amb el concepte de gramaticalització és Traugott (1993 i 1997), la qual estudia el verb threaten anglès i observa un procés gradual de blanqueig semàntic motivat per la subjectivació en diacronia que dona pas al valor epistèmic. Aquesta proposta ha estat àmpliament seguida, complementada i discutida, amb aportacions com la de Verhagen (2000) o Kissine (2010). Destaquen particularment les contribucions de Cornillie (2007), que introdueix el concepte d'evidencialitat a l'estudi del verb amenazar espanyol. I la de Heine i Kuteva (2006), els quals fan una panoràmica de l'evolució dels verbs que expressen el concepte 'amenaçar' en les llengües europees i conclouen que l'evolució paral-lela observada, més que a una tendència general en el procés de gramaticalització, respon a una situació de contacte de llengües; en concret, apunten que el canvi degué engegar-se en francès i difondre's després a la resta de llengües de l'entorn, en un procés que anomenen de gramaticalització induïda per contacte.

La hipòtesi anterior ha estat qüestionada per Cornillie i Octavio de Toledo (2015), els quals estudien en diacronia la construcció [amenazar Vinf] del castellà i conclouen que evoluciona a partir d'una construcció llatina integrada pel verb MINARI complementat per un substantiu deverbal. Segons aquests autors, la 
construcció llatina degué passar a la literatura de tradició humanista com a calc i traslladada a les llengües europees modernes. És d'aquesta construcció primera d'on es desenvoluparan els usos contemporanis, amb una ampliació categorial i semàntica dels tipus de complements que admet el verb.

Si ens centrem en el cas del cat., la lexicografia històrica no aporta informació sobre l'origen del valor epistèmic/evidencial. El significat amb què es pot trobar aquest verb en cat. antic i modern és el primer: 'Fer amenaces' (VFaraudo, s.v. menaçar; DAguiló, s.v. menaçar), és a dir, 'Manifestar amb paraules o amb el gest la intenció de fer mal a qualcú' (DCVB, s.v. amenaçar, 1). Els corpus lingüístics del cat. (CIGCA, CIGCMod i CTILC) ens permeten datar l'expansió del valor epistèmic/evidencial durant el s. XVIII amb complements nominals i situen els primers casos en què el verb, amb aquest valor, introdueix Vinf durant el segon terç del s. XIX. Aquesta dada és coherent amb el fet que el DLabèrnia (1864) és el primer a incloure aquest valor entre les accepcions del verb: 'Estar en próxim perill ó contingéncia de succehir alguna cosa' (s.v. amenassar).

Partint d'aquest estat de la qüestió, en el nostre article provem de descriure i explicar el procés de canvi pel qual el verb amenaçar arriba a desenvolupar, en cat., el valor epistèmic/evidencial durant l'època moderna, en un procés que culminarà ja en el segle XIX. Així, doncs, l'estudi parteix de l'anàlisi quantitativa i qualitativa dels resultats obtinguts de l'anàlisi dels corpus lingüístics de referència (CIGCA, CIGCMod i CTILC), els quals es discutiran en contrast amb les propostes de Traugott (1993 i 1997), Heine i Kuteva (2006), Cornillie (2007) i Cornillie i Octavio de Toledo (2015).

\section{Metodologia}

Aquest estudi es fonamenta en les dades obtingudes de tres corpus lingüístics informatitzats de la llengua catalana, la suma dels quals permet cobrir el conjunt del període objecte d'anàlisi: des dels primers textos conservats (primera meitat del s. XIII) i fins al s. XIX (moment en què trobem plenament desplegat el valor epistèmic/evidencial).

La mostra de la llengua medieval (s. XIII-XVI) prové del Corpus Informatitzat de la Gramàtica del Català Antic (CIGCA), un corpus històric, diacrònic i general de la llengua catalana (per a saber-ne més, vegeu Martines i Sánchez 2014). Per la seua banda, el Corpus Informatitzat de la Gramàtica del Català Modern (CIGCMod) reuneix textos datats entre el 1601 i fins a la data simbòlica del 1833, any en què es convé que s'inicia la Renaixença catalana (per a saber-ne més, vegeu Antolí 2018 i Sánchez 2018). Finalment, per descriure l'evolució de l'ús del verb amenaçar durant el s. XIX, hem fonamentat l'estudi en el buidatge i anàlisi de les dades del Corpus Textual Informatitzat de la Llengua Catalana (CTILC); aquest és també un corpus diacrònic (abraça el període 1833-1987) i de llengua general (vegeu, per a saber més de les característiques del CTILC, Rafel 1994). 
L'estudi es fonamenta en l'anàlisi de la totalitat de la mostra obtinguda (CIGCA: 93 casos; CIGCMod: 122 casos; CTILC (1833-1903): 457 casos). Les dades recuperades han estat analitzades qualitativament i quantitativa, $i$ interpretades mitjançant les eines teòriques de què ens forneix la Lingüística Cognitiva i la Gramàtica de Construccions basada en l'ús, d'acord amb la proposta de Traugott i Trousdale (2016), la Invited Inferencing Theory of Semantic Change (IITSC) de Traugott (2012) i el concepte de subjectivació (d'acord amb la proposta de Traugott i Dasher 2002).

\section{ANÀLisi de RESUltats}

En aquest apartat descriurem els resultats obtinguts dels corpus de referència i els analitzarem en diacronia atenent, d'una banda, el sorgiment i evolució dels nuclis semàntics identificats (\$3.1). I, de l'altra, observant l'evolució en diacronia de les principals variables ateses en l'estudi del procés de gramaticalització del verb amenaçar en altres llengües (remetem a l'estat de la qüestió de §1). D’una banda, atendrem les manifestacions semàntiques i sintàctiques del procés de subjectivació del verb (seguint Company 2004): l'atenuació del control de l'agent sobre la situació descrita pel verb (§3.2), el debilitament del significat referencial del verb, i el consegüent increment de la subjectivitat de la situació descrita (§3.3); i, la realització gramatical del tema (§3.4). Finalment, estudiarem la tipologia textual d'on prové la mostra (§3.5).

\subsection{Descripció semàntica en diacronia}

En el període estudiat, hem identificat huit significats diferents del verb. Tot seguit els definim i descrivim d'acord amb el model establert pel Diccionari Descriptiu de la Llengua Catalana (DDLC). Per a cada accepció, presentem un codi amb el qual la identificarem al llarg de l'estudi ([S ]), la datació del primer cas, el patró sintàctic, la definició i les restriccions semàntiques que afecten els elements lèxics del patró descrit. L'ordenació de les accepcions és cronològica, es correspon amb la datació del primer exemple. En cas que la definició en qüestió conste al $D D L C$, apareix referenciada.

[S1] (s. XIII) [N $\mathrm{N}_{1} \mathrm{~V}\left(a \mathrm{~N}_{2}\right)\left(a m b / d e / a \mathrm{~N}_{3}\right)$ ], [N $\mathrm{N}_{1} \mathrm{~V}\left(a \mathrm{~N}_{2}\right)\left(\right.$ de/a/en) $\left.\mathrm{Vinf}_{3}\right],\left[\mathrm{N}_{1} \mathrm{~V}(a\right.$ $\mathrm{N}_{2}$ ) (que) Vind 3 ]; ( $\mathrm{N}_{1}$ [humà]; $\mathrm{N}_{2}$ [humà]; $\mathrm{N}_{3}$ [mal, càstig]); 'Anunciar [a algú que està en disposició de fer o no fer una cosa] 2 [un mal, un càstig] 3 com a conseqüència' (DDLC, s.v. amenaçar, 2a) ( a mort, $\sim$ amb castics, $\sim$ amb treballs, $\sim$ de pena, $\sim$ de turment). En aquesta primera accepció, el subjecte (d'ara endavant, $\mathrm{S}$ ) té el paper temàtic d'agent i trobem a més dos arguments possibles, el datiu amb paper temàtic de beneficiari $\left(\mathrm{N}_{2}\right)$ i un complement preposicional amb paper de tema $\left(\mathrm{N}_{3}, \mathrm{Vinf}_{3}, \mathrm{Vind}_{3}\right)$. En cat. actual, aquesta estructura sintàctica és estranya i el beneficiari s'expressa com a acusatiu (vegeu [S1.2]). Puntualment trobem un adjunt que expressa el mitjà: $\sim$ de insult, $\sim$ de paraula, $\sim$ en ses lletres. 
(1) a. [...] aqeles companges de les gens qi anaven davant N[ostre] S[einor] manazaven ad aqel ceg e dezien-li qe calàs; e com éls més li manazaven, él màs li cridave: J[hes]u, fili David, m[iserere] m[ei]. (Homilies d'Organyà [XIII], 120, 10-11; CIGCA) ${ }^{3}$

b. $\quad E$ con li menassàs que él lo faria en diverses turmens turmentar, Sent Andreu respòs: [...]. (Vides de Sants Rosselloneses [XIII], 33, 24; CIGCA)

Encabim dins de [S1] el sentit [ $\mathrm{N}_{1} \mathbf{V}\left(\mathrm{N}_{2}\right)\left(a m b \mathrm{~N}_{3}\right)$ ]; ( $\mathrm{N}_{1}$ [humà]; $\mathrm{N}_{2}$ [humà]; $\mathrm{N}_{3}[\text { arma]); 'Donar a entendre [a algú] }]_{2}$ la intenció de fer-li mal [amb una arma] ${ }^{\prime}$ (DDLC, s.v. amenaçar, 1). Aquest sentit varia de l'anterior en el fet que $\mathrm{N}_{3} \mathrm{va}$ introduït per la preposició $a m b$ (o en en valencià a partir del s. XVII) i és una arma $\mathrm{o}$, en general, un instrument que permet infligir sofriment al pacient: generalment un punyal, però també bastó, clau, coltell, daga, dalla, escopeta, ganivet o verga en la llengua antiga i moderna. I si bé és cert que aquest és el significat més freqüent en la llengua actual, és poc habitual en la llengua antiga i moderna, i deriva de l'anterior per restricció, narrowing (partint de la relació metonímica SUBEVENT \& COMPLEX EVENT; Peirsman \& Geeraerts 2006).

(2) Establí Sen Gregori lo ofici el cant de la glesa, e que los clerges tengessen escola de cant. E per aysò él féu fer dos abitàcols, so és, ·II cases: una, costa la glesa, e l'atra [costa la glesa] de Latrà [...]. E s'í mostra la sua verga, ab què menassava als escolàs. (Vides de Sants Rosselloneses [XIII], 308, 14; CIGCA)

I si bé les dues estructures anteriors són intransitives, també el verb es realitza com a transitiu i varia segons si el CD és el pacient o el tema. En el primer cas, es tracta d'una variació tardana, testimoniada al corpus al s. XVI en textos de cat. occidental. Aquesta solució acabarà imposant-se a la realització intransitiva del verb [S1].

(3) Ý sabent jo asò, determiní de anar-li a parlar, a dita na Gojona. Ý li diguí-ý amenassant-la que dit mon fill estave mal des que havie menjat los aubercochs que ella li havie donats, ý que 1 me anàs a curar, si no, que li costarie. (La llengua dels processos de crims a la Lleida del segle XVI [XVI], 200v, 3; CIGCA)

En segon lloc, l'objecte pot ser el tema, és a dir, el mal, el càstig amb què s'amenaça. Els primers dos casos en què trobem un substantiu fent aquesta funció són del s. XIV i del s. XV. Amb una completiva, és una estructura difícil d'identificar i de datar fruit de la caiguda de la preposició davant la conjunció que, de manera que la datació ha de ser indirecta, quan trobem que es pronominalitza el tema amb el neutre ho (s. XV, exemple 4).

(4) [...] segons affermen [...] se poria seguir dilació al espetxament dels $\cdot L_{-}$milia florins a vostra senyoria per la dita Cort novellament atorgats e consentits, e axí ho menassen que $\mathrm{u}$ faran tro lo dit greuge sia per justícia bé provehit. (Epistolari de Ferran I d'Antequera [XV], carta 102, 44; CIGCA)

\footnotetext{
${ }^{3}$ La referència dels exemples segueix el patró següent: (Autor (si escau), Títol de l'obra [segle], pàgina, línia; corpus).
} 
[S2] (s. XV) [ $\left.\mathrm{N}_{1} \mathbf{V ~ N} \mathrm{N}_{2}\left(a \mathrm{~N}_{3}\right)\right],\left[\mathrm{N}_{1} \mathbf{V}\left(a \mathrm{~N}_{2}\right)\right.$ (de/amb) Vinf $\left.3 \mathrm{i}\right],\left[\mathrm{N}_{1} \mathbf{V}(a) \mathrm{N}_{3}\right]$; $\left(\mathrm{N}_{1}\right.$ [humà]; $\mathrm{N}_{2}$ [mal, càstig]; $\mathrm{N}_{3}$ [humà, cosa]); 'Estar a punt d'infligir [un mal] 2 [a algú, a alguna cosa] $3^{\prime}$. Es tracta d'un significat amb un major component epistèmic, en tant que si bé el $S$ és agentiu, l'amenaça expressada resulta de la interpretació que fa el locutor/conceptualitzador (d'ara endavant L/C) de la voluntat del S, i no d'un anunci explícit d'aquell (com en [S1]). D'aquesta manera, el verb amenaçar manifesta en el discurs la perspectiva subjectiva del L, i això de dues maneres: d'una banda, en tant que la informació enunciada resulta de l'avaluació subjectiva del L/C; i, de l'altra, perquè aquell qualifica com a negatiu l'esdeveniment.

(5) [...] la necessitat ab què-s troba la província de tràurer lo enemich d'ella, qui occasiona tots los danys que vuy suporta y encara ne amanassa molts altres més si no se acut ab poder a esta empresa [...]. (Dietari de la Generalitat de Catalunya 1644-1647 [XV], 44, 74; CIGCMod)

[S3] (s. XV) [ $\mathrm{N}_{1} \mathbf{V}\left(a \mathrm{~N}_{2}\right)$ ], [ $\mathrm{N}_{1} \mathbf{V}\left(\mathrm{N}_{2}\right)$ ]; (N1 $\mathrm{N}_{1}$ perill, mal], $\mathrm{N}_{2}$ [humà, cosa]); '[Un perill, un mal]1 presentar-se [a algú, alguna cosa] 2 com a probable' (DDLC, s.v. amenaçar, 3). Amb aquest valor, el verb expressa que, d'acord amb l'avaluació del L/C, és probable en el futur la realització de l'esdeveniment negatiu que expressa el S (càstig, mal, perill, ruïna, tragèdia, treball). En aquest context, l'agent humà responsable de la realització de l'esdeveniment previst es desdibuixa en el discurs (6a, un motí), quan no és un esdeveniment independent de la voluntat humana (6b, una epidèmia).

(6) a. Negaren al retor la asistència de la sera per a misses i demés funcions parroquials [...] y reparant el retor que la falta de funcions de la església podia ocasionar major mal en lo comú que per major part sentien estes coses, [...], determinà en avant costegar de propis ý adelantar lo gasto necessari en la església que a son tems es podia recobrar, ý se evità així el motí que algun dia amenasava. (Josep Esplugues, Memòries [XVIII], 129, 24; CIGCMod)

b. Que per medi de un ciutadà y un militar del present Consell se fassa una Embaixada al molt Ill.e Capítol de la present ciutat dient-los que la present Ciutat per a què Déu nostre Senyor sie servit per sa infinita misericòrdia y bondat preservar esta Ciutat del mal contagiós que-ns amenassa, desijaria a demés dels Sancts protectors té péndrer per protector y advocat Sanct Fransisco de Paula [...]. (Manual de novells ardits [XVII], 119, 113; CIGCMod)

[S4] (s. XIV) [ $\mathrm{N}_{1} \mathbf{V}\left(\begin{array}{lll}\text { a } & \mathrm{N}_{2} & \mathrm{~N}_{3}\end{array}\right],\left[\mathrm{N}_{1} \mathbf{V}\left(a \mathrm{~N}_{2}\right)\right.$ que Vind 3 ; ( $\mathrm{N}_{1}$ [pronòstic], $\mathrm{N}_{2}$ [humà, cosa], $\mathrm{N}_{3}\left[\right.$ mal presagi]); '[Un pronòstic]1 anunciar [a algú]2 [un mal] ${ }_{3}$ ' Aquest és un significat singular (i poc freqüent) en què el L no exerceix de C, però el $S$ tampoc no és agent, sinó el mitjà que anuncia un presagi.

(7) Dimarts a 15 los consellers de Barcelona enviaren a sercar los priors dels cònsols dels artistes y los prohoms de les confraries perquè vejan les armes que tenen y's posen a punt de guerra, perquè lo pronòstich de $\mathrm{T}$. Oller, presbítero de Barcelona ${ }_{\mathrm{L}}$ amenaça $\mathrm{a}$ aquesta ciutat per a 24 de juny, que tindrà necessitat de tocar alarma y en juliol sobresalt de enemichs. (Jeroni Pujades, Dietari [XVII], 161, 9; CIGCMod) 
[S5] (s. XVII) [VPRON $\mathrm{N}_{1}$ (a $\left.\mathrm{N}_{2}\right)$ ]; ( $\mathrm{N}_{1}$ [perill, mal], $\mathrm{N}_{2}$ [humà, cosa]); 'Presentar-se [un perill, un mal] $]_{1}$ [a algú] $]_{2}$ com a probable'. És un significat proper semànticament a [S3] pel fet que la possibilitat que l'esdeveniment anunciat (calamitat: 8b, càstig, desditxa: 8a, mal, plaga, treball) resulta de la interpretació del L/C a partir d'un estat de coses i no de la voluntat anunciada d'altri, però se'n distancia en tant que el mal previst es realitza com a acusatiu i la construcció com a impersonal.

(8) a. En aquest dia se tingue Concell de cent en lo qual entre altres cosas se tractaren fou deslliberar que los srs. Concellers fessan una Junta de las personas los aparexaria per a veurar y mirar los medis y camins mes convenients se porian trobar per a extirpar los vicis y pacats se fan en la present Ciutat peraque d'exa manera Déu nostre Sr. per sa infinita bondat y misericòrdia volgués preservar-nos de las desditxas se'ns amanassan tant per raho de la pesta que i ha en la Ciutat de Girona y vilas sircunveïnas com encara per la mala anyada del blat [...]. (Manual de novells ardits [XVII], 58, 34; CIGCMod)

b. $\quad$ Y com estant la major part de la província tant apretada y afligida, com és públich, [...] sia molt just acudir a Déu, Nostre Senyor, ab pregàries y devocions per a què, usant de sa acostumada clemèntia, vulla preservar-nos de les calamitats que per tantes vies se·ns amenassan [...]. (Lletres Reials a la Ciutat de Girona [XVII], 1326, 17; CIGCMod)

[S6] (s. XVII) [ $\mathrm{N}_{1} \mathrm{~V}\left(\mathrm{~N}_{2} / \mathrm{Vinf}_{2}\right)$ ]; ( $\mathrm{N}_{2}$ [esdeveniment advers]); '[Un estat de coses] donar senyals d'estar a punt d'ocórrer [un esdeveniment advers]2' (DDLC, s.v. amenaçar, 5). Amb aquest significat, proper semànticament a [S3] i a [S5], el verb col-loca exclusivament des del s. XVIII amb els substantius pluja (9a) i rü̈na (9b) (anteriorment, durant el XVII, testimoniem tempesta; exemple 9c), i sols puntualment el trobem en usos absoluts però en els mateixos contextos (9d). En el context meteorològic, el S són els substantius cel o núvol; si l'esdeveniment advers és la ruïna d'una construcció, el S és l'element arquitectònic. Durant el període 1833-1903, es constata l'ampliació del tipus d'infinitius que admet, si bé amb la restricció que seleccionen un $S$ pacient, que explicita l'estat de coses que, per l'aparença i/o els coneixements de què disposa el L, fonamenta la predicció enunciada (exemple 9e).

(9) a. Dia 14 d'abril [...] alguns [núvols] en la tarda a quatre hores han enfosquit bé lo cel, amenaçant pluja en totes aquelles muntanyes des de ponent a llevant. I en efecte, veient lo doctor Josep Casas i jo, tement-nos de pluja, [...] pareixent que la pluja nos aconseguiria, hem abreviat lo passeig entrant-nos al Born, Sombrerers i principi del carrer de l'Argenteria, fins juntar-nos al de Bòria; havent allí començat la pluja ab algunes poques gotes, i luego començant a rajar les canals. (Rafael d'Amat i de Cortada, Calaix de Sastre (1815-1816) [XIX], 123, 37; CIGCMod)

b. $\quad[\ldots]$ per a què no y agués una total desgràcia en la igléssia, es donà providència per a què se apuntalàs el pilar de la arcada vella que estava amenasant total ruhina. (Les actes capitulars de la seu de Xàtiva [XVIII], 520, 7; CIGCMod)

c.Dilluns a 8 de juny 1609 envés les deu hores de matinada se conturbà lo cel amenaçant gran tempestat, y per totes les isglésies tocaren les campanes, y quant vingué entre la una y las dos fins a les sinc de tarda, se apretaren los núvols ab una foscor tant gran que espantava. [...] a les dos hores començà a desplegar en aygua devés lo Prat y algunes 
gotes en Barcelona. Y incessantment lo temporal ara senyalava a un lloch ara a altro. Fins a les sis de tarda que entre sinc y sis desplegà gran fúria de aygua y serenà lo temps. (Jeroni Pujades, Dietari [XVII], 105, 9; CIGCMod)

d. No podia ser la intenció dels administradors de la obra derrocar per a abolir tal capella quant el conservar-la per lo error comés al principi en no aver-la derrocada del tot, ha causat molt gasto, avent de renovarar-li les parets per les quals amenasava la obra nova. (Josep Esplugues, Memòries [XVIII], 150, 24; CIGCMod)

e. $\quad$ Son pare ha tingut avuy un atach de feridura que amenassa repetir-se. (Lluís Bertran Canudas, Qüestió de nom [XIX]; CIGCMod)

[S7] (s. XIX) [ $\mathrm{N}_{1} \mathrm{~V} \mathrm{~N}_{2}$ ]; ( $\mathrm{N}_{1}$ [cosa, situació]; $\mathrm{N}_{2}$ [cosa, humà]); ‘[Alguna cosa]1 constituir un risc de dany per a [algú, alguna cosa]2' (DDLC, s.v. amenaçar, 4). En aquesta accepció, el S és la causa de l'estat de coses descrit pel verb: l'amenaça és inherent al S: per la constitució, la posició, l'ús o l'evolució descrita (exemple $10)$.

(10) Com era possible callàs nostra llengua quant pareixia ressonar en nostres oïdos lo estrèpit dels canons i morters precursor de la destrucció y de la mort, y semblava sentir-se sobre nostres caps lo xiulet de las incendiàrias bombas que amenassavan nostra existència? (Pere Roquer i Pagani, Indústria catalana [XIX]; CTILC)

[S8] (s. XIX) [ $\mathrm{N}_{1} \mathrm{~V} \mathrm{~N} \mathrm{~N}_{2} / \mathrm{Vinf}_{2}$; ( $\mathrm{N}_{1}$ [cosa, situació], $\mathrm{N}_{2} /$ Vinf2 [esdeveniment advers]); '[Alguna cosa] 1 donar motius per a témer [un perill, un mal] ${ }_{2}$. Com en [S7], el S és l'origen - no intencionat, sinó per raons intrínseques - de l'estat descrit pel verb, mentre que el perill descrit s'expressa en acusatiu, com a $\mathrm{N}$ o Vinf (exemple 11).

(11) ¿Res vol dir que si la situació anòmala del Canal de Urgell, amenassa arruinar eixas comarcas, tinguin los regants interesats de recórrer á representants d' altres provincias á fi de que'ls procurin un èxit favorable en sas gestions justificadíssimas? ( $L o$ Garbell. Periódich clá y catalá, 7 [XIX]; CTILC)

La Taula 1 mostra les freqüències absolutes de cadascun dels significats anteriors en diacronia; la Figura 1 presenta l'evolució del pes percentual de cadascuna de les accepcions durant el període estudiat. 
Taula 1. Evolució de la freqüència absoluta dels significats del verb amenaçar (s. XIII-1903)

\begin{tabular}{|c|c|c|c|c|c|c|c|c|c|c|c|c|c|c|c|c|c|c|}
\hline \multirow{2}{*}{ Període } & \multicolumn{2}{|c|}{ [S1] } & \multicolumn{2}{|c|}{ [S2] } & \multicolumn{2}{|c|}{ [S3] } & \multicolumn{2}{|c|}{ [S4] } & \multicolumn{2}{|c|}{ [S5] } & \multicolumn{2}{|c|}{ [S6] } & \multicolumn{2}{|c|}{ [S7] } & \multicolumn{2}{|c|}{ [S8] } & \multicolumn{2}{|c|}{ Total } \\
\hline & $\mathrm{fi}_{\mathrm{i}}$ & $\%$ & $f_{i}$ & $\%$ & $\mathrm{f}_{\mathrm{i}}$ & $\%$ & $\mathrm{f}_{\mathrm{i}}$ & $\%$ & $\mathrm{f}_{\mathrm{i}}$ & $\%$ & $\mathrm{f}_{\mathrm{i}}$ & $\%$ & $\mathrm{f}_{\mathrm{i}}$ & $\%$ & $\mathrm{f}_{\mathrm{i}}$ & $\%$ & $\mathrm{fi}_{\mathrm{i}}$ & $\%$ \\
\hline s. XIII & 20 & 100,0 & 0 & 0,0 & 0 & 0,0 & 0 & 0,0 & 0 & 0,0 & 0 & 0,0 & 0 & 0,0 & 0 & 0,0 & 20 & 100,0 \\
\hline s. XIV & 24 & 96,0 & 0 & 0,0 & 0 & 0,0 & 1 & 4,0 & 0 & 0,0 & 0 & 0,0 & 0 & 0,0 & 0 & 0,0 & 25 & 100,0 \\
\hline s. XV & 26 & 86,7 & 1 & 3,3 & 2 & 6,7 & 1 & 3,3 & 0 & 0,0 & 0 & 0,0 & 0 & 0,0 & 0 & 0,0 & 30 & 100,0 \\
\hline s. XVI & 17 & 94,4 & 1 & 5,6 & 0 & 0,0 & 0 & 0,0 & 0 & 0,0 & 0 & 0,0 & 0 & 0,0 & 0 & 0,0 & 18 & 100,0 \\
\hline s. XVII & 38 & 64,4 & 2 & 3,4 & 7 & 11,9 & 6 & 10,2 & 5 & 8,5 & 1 & 1,7 & 0 & 0,0 & 0 & 0,0 & 59 & 100,0 \\
\hline s. XVIII & 31 & 59,6 & 3 & 5,8 & 9 & 17,3 & 0 & 0,0 & 3 & 5,8 & 6 & 11,5 & 0 & 0,0 & 0 & 0,0 & 52 & 100,0 \\
\hline $1800-1832$ & 5 & 45,5 & 1 & 9,1 & 3 & 27,3 & 0 & 0,0 & 0 & 0,0 & 2 & 18,2 & 0 & 0,0 & 0 & 0,0 & 11 & 100,0 \\
\hline $1833-1903$ & 246 & 53,9 & 32 & 7 & 77 & 16,8 & 4 & 0,9 & 2 & 0,4 & 39 & 8,5 & 27 & 5,9 & 30 & 6,5 & 457 & 100,0 \\
\hline Total & 407 & & 40 & & 98 & & 12 & & 10 & & 48 & & 27 & & 30 & & 672 & \\
\hline
\end{tabular}

Figura 1. Evolució del pes percentual dels significats del verb amenaçar (s. XIII-1903)

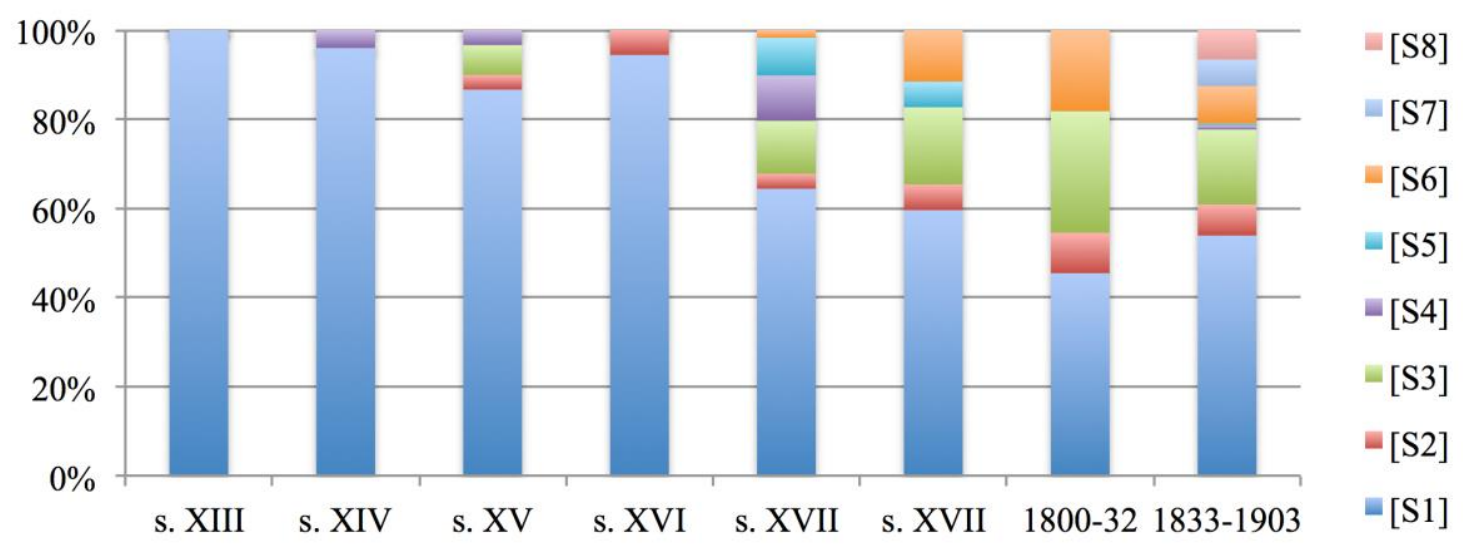

De les dades anteriors, es poden establir tres fases en l'evolució del verb que es corresponen amb la periodització de l'evolució general de la llengua: en cat. antic (s. XIII-XVI), el verb presenta un sol nucli semàntic rellevant: [S1], amb un pes del 93,5\% de la mostra durant el període. Els significats amb component epistèmic, si bé es testimonien en cat. antic (s. XIV: [S4], s. XV: [S2], [S3]), no s'estendran en l'ús i es diversificaran fins al s. XVII i ja en cat. modern (s. XVII1832). En aquesta segona etapa, observem que es consoliden $i$ creixen en general els significats epistèmics que apareixen en cat. antic i durant el s. XVII ([S5], [S6]), els quals representen el $60 \%$ de la mostra durant el període. Finalment, l'etapa 1833-1903 constitueix una fase d'estabilització del procés de canvi constatat, amb la consolidació de dos nuclis semàntics amb un pes percentual similar (al voltant de la meitat dels casos): el primer amb un $\mathrm{S}$ agentiu i el segon epistèmic, i el sorgiment de dos nous significats epistèmics: [S7] i [S8].

\subsection{Agentivitat del subjecte}

Quan parlem de l'agentivitat del S, ens referim a la coincidència del S sintàctic amb el paper temàtic d'agent, és a dir, la funció semàntica de «l'entitat animada que instiga de manera voluntària una acció o esdeveniment» (Bel 2002, 1081); és 
un tret vinculat a la intencionalitat de l'esdeveniment descrit pel verb i generalment al caràcter [+humà] del S. Per contra, l'atenuació de l'agentivitat del $S$ és una de les conseqüències sintàctiques aparellades al procés de subjectivació semàntica d'una expressió (Company 2004, entre d'altres).

Quant al verb amenaçar, [S1] (i tots els sentits que aplega) i [S2] es caracteritzen per seleccionar un $S$ [+agentiu]. Caldria matisar que, d'acord amb la mostra, aquesta agentivitat es pot veure atenuada fer 5 factors principalment:

a) El subjecte/agent (S/A) és col·lectiu (1a datació s. XIII; exemple 12).

(12) [...] los jueus agren d'él envega; per què [...] menassaren-li que·l farien cruelment turmentar. (Vides de Sants Rosselloneses [XIII], 80, 25; CIGCA)

b) El S/A és un ésser sobrenatural (concretament, la divinitat; 1a datació s. XIII; exemple 13). En aquest context, l'amenaça deriva de l'exegesi que fa el L, potser dels textos sagrats.

(13) [...] e açò per tal quant gita de nós la mortal ignorància, per la qual Déu nos ha menassat que-ns oblidarà e.ns turmentarà ací en vida, e puys nos dampnarà si ella nos amaga [...]. (Francesc Eiximenis, Dotzè del Crestià [xv], 21, 32; CIGCA)

c) El S/A expressa la seua intenció de manera mediata, a través d'un escrit (1a datació s. XIV; exemple 14).

(14) [...] Cada nit plantavan papers per los cantons de dita ciutat amanassent al Virey Tasorer y ha alguns jutges que si no feian que dits srs. tornassen al exercici dels puestos que-ls avian tres que.ls matarian [...]. (Un interessant manuscrit sobre la Revolta dels Barretines [XVIII], 83, 69; (IGCMod)

d) Contextualment és possible que reste omès el $S$, en construccions passives o impersonals (1a datació, per a casos de S agent, del s. XVIII; exemples 15a i 15b).

(15) a. [...] es tragué segon ý después tercer, ý en éste se li amenasà la pena rigurosa de la excomunió, si no obeïa. (Josep Esplugues, Memòries [XVIII], 137, 14; CIGCMod)

b. $\quad[\ldots]$ se necessitien en atenció de què los batlles són amenassats en cas volguessen executar los ordes ab que.s trobe [...]. (Diplomatari de la Vall d'Andorra [XVIII], 160, 12; CIGCMod)

e) El S/A és una personificació, especialment en textos de finalitat literària (1a datació s. XIV; exemple 16).

(16) -A Melchior, pare meu! Prech-te, si ésser pot, que cerchs altra via a ma consolació, e, ab los ulls de la pensa, mira la color del meu cor. Vet la mort que $\cdot m$ menaça, cuydant-se que yo la tema; no sab ella bé ço que yo aparell per a seguir-la, sinó pus pereosament se mouria per venir a mi. (Enyego d'Àvalos [?], Curial e Güelfa [Xv], 264, 9; CIGCA)

Els significats següents ([S3]-[S6]) tenen en comú un S [-agentiu]; el prototipus d'aquesta modalitat el constitueixen casos com el de 9a «alguns 
[núvols] en la tarda a quatre hores han enfosquit bé lo cel, amenaçant plują, en què la realització de l'estat de coses futur presentat com a possible pel verb no depèn de la voluntat de cap agent. En altres contextos, aquest caràcter [-agentiu] es troba atenuat en tant que, si bé el $S$ no és agent, la realització d'aquest estat de coses implica un agent (exemple 17).

(17) [...] no faltant als baluarts y demés puestos exposats tant los soldats com los de la Coronela, que, igualment com aquells, acudían animosament a dits puestos y, per lo cas de un assalt, se anàvan disposant per part dedins fossos y cortaduras corresponents a las parts per haont amenassava la invasió. (Manuel Mas i Soldevila, Relació del siti de Barcelona [XVIII], 65, 1133; CIGCMod)

La Taula 2 mostra l'evolució en freqüència absoluta de les diferents modalitats d'aquesta variable en diacronia, mentre que la Figura 2 presenta l'evolució d'acord amb el pes percentual de cada modalitat per període cronològic. La modalitat [+agentiu] es refereix a aquells casos en què el $S$ sintàctic coincideix amb el paper temàtic d'agent, $\mathrm{i}$ és una entitat animada $\mathrm{i}$ prototípicament humana que executa voluntàriament l'acció descrita pel verb. La modalitat [+agentiu]* agrupa aquells casos en què el $S$ és agent, però en els quals alhora es dona algun dels contextos atenuants descrits anteriorment (contextos a-e; exemples 12-16). La modalitat [-agentiu] correspon a aquells casos en què hi ha un debilitament de l'agentivitat o inclús una pèrdua del control de l'agent sobre l'esdeveniment, en aquells contextos en què el $S$ sintàctic recau sobre una entitat inanimada no agentiva, mancada de voluntat $i$, doncs, que no pot realitzar voluntàriament l'acció descrita pel verb. En quart lloc, la modalitat [-agentiu] aglutina els casos en què el caràcter [-agentiu] es troba atenuat, com ja hem dit, pel fet que la realització de l'estat de coses descrit pel verb implica un agent (exemple 17).

Taula 2. Evolució de la freqüència absoluta de les modalitats de la variable agentivitat del subjecte (s. XIII-1903)

\begin{tabular}{|c|c|c|c|c|c|c|c|c|c|c|}
\hline \multirow{2}{*}{ Període } & \multicolumn{2}{|c|}{ [+agentiu] } & \multicolumn{2}{|c|}{ [+agentiu]* } & \multicolumn{2}{|c|}{ [-agentiu] ${ }^{*}$} & \multicolumn{2}{|c|}{ [-agentiu] } & \multicolumn{2}{|c|}{ Total } \\
\hline & $\mathrm{fi}_{\mathrm{i}}$ & $\%$ & $\mathrm{fi}_{\mathrm{i}}$ & $\%$ & $\mathrm{fi}_{\mathrm{i}}$ & $\%$ & $\mathrm{f}_{\mathrm{i}}$ & $\%$ & $\mathrm{f}_{\mathrm{i}}$ & $\%$ \\
\hline s. XIII & 13 & 65,0 & 7 & 35,0 & 0 & 0,0 & 0 & 0,0 & 20 & 100,0 \\
\hline s. XIV & 22 & 88,0 & 2 & 8,0 & 0 & 0,0 & 1 & 4,0 & 25 & 100,0 \\
\hline s. XV & 19 & 63,3 & 9 & 30,0 & 0 & 0,0 & 2 & 6,7 & 30 & 100,0 \\
\hline s. XVI & 15 & 83,3 & 3 & 16,7 & 0 & 0,0 & 0 & 0,0 & 18 & 100,0 \\
\hline s. XVII & 33 & 55,9 & 6 & 10,2 & 8 & 13,6 & 12 & 20,3 & 59 & 100,0 \\
\hline s. XVIII & 22 & 42,3 & 12 & 23,1 & 8 & 15,4 & 10 & 19,2 & 52 & 100,0 \\
\hline $1800-32$ & 3 & 27,3 & 2 & 18,2 & 3 & 27,3 & 3 & 27,3 & 11 & 100,0 \\
\hline $1833-03$ & 170 & 37,2 & 108 & 23,6 & 61 & 13,3 & 118 & 25,8 & 457 & 100,0 \\
\hline Total & 297 & & 149 & & 80 & & 146 & & 672 & \\
\hline
\end{tabular}


Figura 2. Evolució del pes percentual de les modalitats de la variable agentivitat del subjecte (s. XIII-1903)

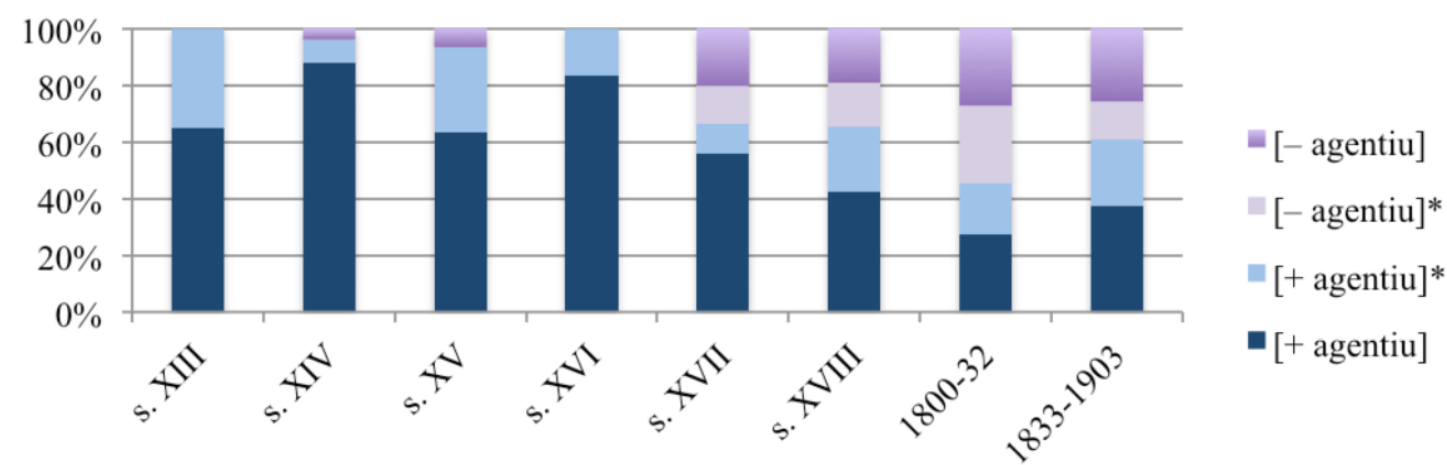

Observem en diacronia l'aparició (s. XIV), consolidació (s. XVII) i expansió en l'ús progressiva (s. XVIII-XIX) dels casos amb un S [-agentiu], que durant el període 1833-1903 arriba a representar gairebé el 40 \% de la mostra. Així, doncs, s'observa una caiguda gradual del pes relatiu dels casos amb un S [+agentiu] (cat. antic: 96,8 \%, cat. modern: 63,9\%, 1833-1903: 60,8 \%), al ritme que creixen els casos amb S [-agentiu] (cat. antic: 3,2 \%, cat. modern: 36,1 \%, 1833-1903: 39,2 $\%)$. És significatiu, així mateix, el creixement en diacronia dels casos amb el tret [+/-agentiu] atenuat (cat. antic: 22,6 \%, cat. modern: $32 \%, 1833-1903: 37 \%$ ).

\subsection{Subjectivitat de la situació descrita pel verb}

Vinculada amb l'agentivitat del S, hi ha el grau de subjectivitat de la situació descrita pel verb. La diferència entre l'objectivitat i la subjectivitat d'una expressió s'ha explicat partint del grau d'implicació del locutor. D'aquesta manera, Traugott i Dasher (2002: 22-23) consideren «those expressions most objective that require the fewest inferences depending on SP/W-AD/R» (on SP equival al locutor, $\mathrm{W}$ a l'escriptor, $\mathrm{AD}$ al receptor i $\mathrm{R}$ al lector). En canvi, s'entén la subjectivitat com «the way in which natural languages, in their structure and their normal manner of operation, provide for the locutionary agent's expression of himself and his own attitudes and beliefs» (Traugott 2010, seguint Lyons 1982: 102). ${ }^{4}$ Val a dir que la diferència entre subjectivitat i objectivitat és gradual. Així, doncs, com bé apunta Company (2004: 4) «A menor

${ }^{4}$ Amb més detall, les característiques que defineixen les expressions objectives, segons Traugott i Dasher (2002: 22-23) són: «(i) they are declarative, i.e. minimally marked with regard to modality; (ii) all participants in an event structure are expressed in surface structure; (iii) lexical items are minimally concerned with the interlocutors' perspective (i.e. minimally deictic); (iv) the Q-heuristic predominates, i.e. contexts for meanings are provided so that interpretation is strongly determinated, and what is not said is implied not to be the case». Per contra, les expressions subjectives es defineixen per ser (Traugott i Dasher 2002: 23): «(i) overt spatial, and temporal deixis; (ii) explicit markers of SP/W attitude to what is said, including epistemic attitude to the proposition; (iii) explicit markers of SP/W attitude to the relationship between what precedes and what follows, i.e. to the discourse structure [...]; (iv) the R-heuristic predominates». 
involucramiento, el enunciado será más objetivo -o menos subjetivo-, a mayor involucramiento del hablante, el enunciado será más subjetivo».

$\mathrm{D}^{\prime}$ acord $\mathrm{amb}$ aquesta distinció, en [S1] el verb presenta un significat poc subjectiu, referencial; descriu un esdeveniment, en concret una realització, l'acte comunicatiu en què el $S$ emet unes paraules d'amenaça en contra d'algú que prototípicament és present i les rep sense mediació. El més freqüent és trobar el verb conjugat en aspecte perfectiu, la qual cosa és coherent amb una caracterització d'aquest com a realització (exemple 18).

(18) [...] aquest testis menassà a la dita esclava fort dient-li que, si ella no li dehia què havia feta [de] la dita letra, que ell la consumaria. E la dita esclava dix a aquest testis que la dita letra havia es[cr]i[t]a $\cdot \mathrm{I} \cdot$ fill d'en Alamany [...]. (Procés criminal contra Antònia Marquès [XIV], 3v, 2; CIGCMod)

Ara bé, no podem qualificar aquest valor d'objectiu en tant que, seguint l'argumentació de Verhagen (2000), amenaçar és un verb relativament subjectiu ja en el significat primer (i a diferència, en concret, de prometre), en tant que és el L qui qualifica (de forma negativa) com a amenaça les paraules o el gest en qüestió: en l'exemple 18 és el L (i no el S) qui categoritza d'amenaça l'acte de parla pel qual el $S$ digué a la interlocutora que «si ella no li dehia què havia feta [de] la dita letra, que ell la consumaria».

D'acord amb el que s'acaba d'apuntar, per a la variable de la subjectivitat del verb podem reconèixer les modalitats [+subjectiu] i [-subjectiu], i la possibilitat que aquestes es troben atenuades. El tret [-subjectiu] és propi de [S1], com hem argumentat partint de l'exemple (18), i el trobem atenuat en els contextos següents:

a) Aquells en què el L no es limita a descriure un esdeveniment (un acte de parla) concret en què el $S$ anuncia l'amenaça, sinó que presenta un esdeveniment iterat (exemple 19a) o una situació abstracta i durativa en què l'amenaça és vigent (exemple 19b). En exemples com (18), el grau de processament cognitiu de la informació per part del L és baix (ens situem en habilitats de pensament de rang inferior recordar i comprendre, d'acord amb la taxonomia de Bloom), mentre que en (19a) i (19b) no es limita a descriure la situació, sinó que la interpreta i sintetitza. Aquesta nova caracterització semàntica es tradueix en l'ús de temps verbals d'aspecte imperfectiu. És freqüent que aquesta matisació del caràcter [-subjectiu] vaja aparellada amb una atenuació del caràcter [+agentiu], com en (19b).

(19) a. Y fonch lo cas que dit doctor Sabata amenasava que havia de matar a una cosina seua, filla de sa tia, perquè no vivia ab lo recato que devia. (Joaquim Aierdi, Dietari [XVII], 180, 15; CIGCMod)

b. $\quad Y$ d'erra tan gran faràs gran esmena / perquè nostra pàtria no porgue tal crim, / car Déu nos menaça de molt justa pena / hi·l cel vol ja caure damunt nostra squena / ab lo terratrèmol tan gran que sentim. (Lo passi [XV], 4125; CIGCA) 
b) En segon lloc, incloem dins de l'atenuació de la modalitat [-subjectiva] els contextos en què l'amenaça no es produeix de paraula, sinó que és indirecta mitjançant l'ús d'armes.

(20) E no contents de dits robos, mas encara ab balestes parades y spases tirades, han manassat la noble senyora dona Joana de Lachs, abbadessa, alsguns d'ells tancant-li la boca perquè no cridàs [...]. (La llengua dels processos de crims a la Lleida del segle XVI [XVI], 22r, 22; CIGCA)

Finalment, incloem en la modalitat [+subjectiu] tots els casos dels significats amb component epistèmic, també els de [S2], amb un $S$ [+humà] i [+agent], però en els quals l'esdeveniment previst deriva de la interpretació del $\mathrm{L} / \mathrm{C}$ de la intenció del S.

(21) Molt car primogènit: Bé sabets les grans e excessives messions e despeses que fem incessantment e los càrrechs que portam, los quals nos crexen de dia en dia axí per rahó de [...] aquelles més gents d'armes e ballesters, de què-ns cové créxer e soldejar per raó de la nova que havem haüda de les gents d'armes stranyes que menassen de entrar [...]. (Epistolari de Ferran I d'Antequera [XV], carta 133, 13; CIGCA)

Taula 3. Evolució de la freqüència absoluta de les modalitats de la variable subjectivitat (s. XIII1903)

\begin{tabular}{|c|c|c|c|c|c|c|c|c|c|c|c|c|c|c|c|c|}
\hline \multirow{2}{*}{ Modalitat } & \multicolumn{2}{|c|}{ XIII } & \multicolumn{2}{|c|}{ XIV } & \multicolumn{2}{|c|}{$\mathbf{X V}$} & \multicolumn{2}{|c|}{ XVI } & \multicolumn{2}{|c|}{ XVII } & \multicolumn{2}{|c|}{ XVIII } & \multicolumn{2}{|c|}{$1800-1832$} & \multicolumn{2}{|c|}{ 1833-1903 } \\
\hline & $f_{i}$ & $\%$ & $f_{i}$ & $\%$ & $\mathrm{f}_{\mathrm{i}}$ & $\%$ & $f_{i}$ & $\%$ & $f_{i}$ & $\%$ & $\mathrm{f}_{\mathrm{i}}$ & $\%$ & $f_{i}$ & $\%$ & $f_{i}$ & $\%$ \\
\hline [+subjectiva] & 0 & 0 & 1 & 4 & 4 & 13,3 & 1 & 5,6 & 22 & 37,3 & 22 & 42,3 & 7 & 63,6 & 214 & 46,8 \\
\hline [-subjectiva] atenuada & 6 & 30 & 4 & 16 & 9 & 30,0 & 5 & 27,8 & 14 & 23,7 & 21 & 40,4 & 2 & 18,2 & 90 & 19,7 \\
\hline [-subjectiva] & 14 & 70 & 20 & 80 & 17 & 56,7 & 12 & 66,7 & 23 & 39,0 & 9 & 17,3 & 2 & 18,2 & 153 & 33,5 \\
\hline Total & 20 & 100 & 25 & 100 & 30 & 100 & 18 & 100 & 59 & 100 & 52 & 100 & 11 & 100 & 457 & 100 \\
\hline
\end{tabular}

Figura 3. Evolució del pes percentual de les modalitats de la variable subjectivitat (s. XIII-1903)

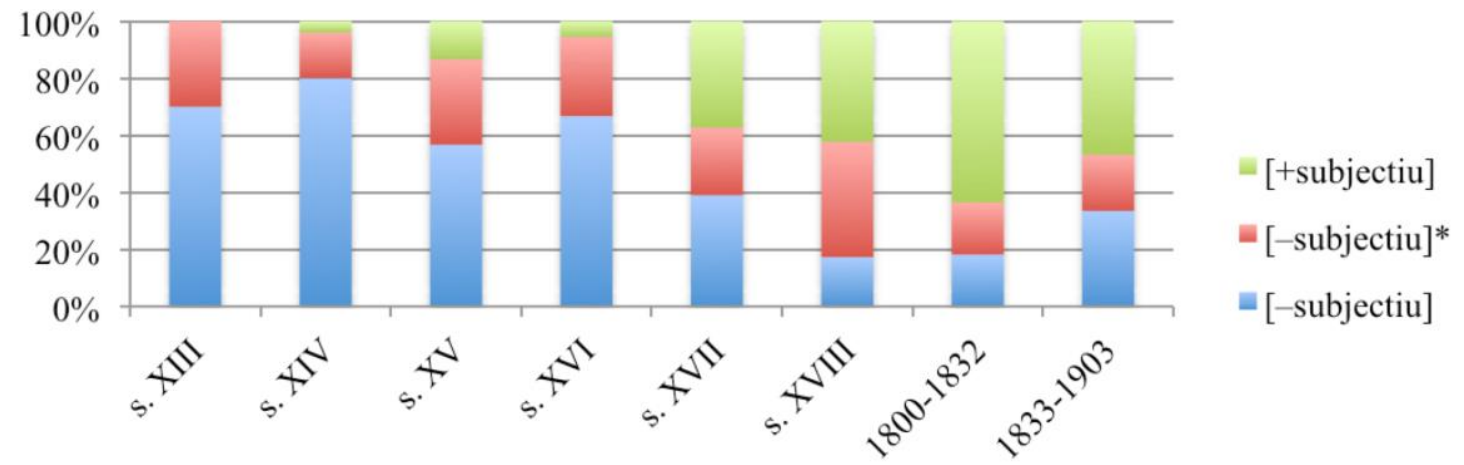

Observem en diacronia l'aparició (s. XIV), consolidació (s. XVII) i expansió en l'ús progressiva (s. XVIII-XIX) de la modalitat [+subjectiu]. D'aquesta manera, mentre que en cat. antic (s. XIII-XVI), la modalitat [+subjectiu] representa el 6,5\% dels casos, en cat. modern (s. XVII-1832) equival al 41,8 \% dels casos i durant el període 1833-1903 assoleix el 46,8 \% de la mostra. És significatiu també el fet que la mostra de la modalitat [-subjectiu] atenuada té un pes percentual rellevant per a tot el període estudiat, del 22,5\%. 


\subsection{Realització gramatical del tema}

La tercera variable atesa en aquest estudi és el tipus de realització gramatical del tema. És una qüestió significativa a l'hora de descriure el possible procés de gramaticalització del verb, i així ha estat tractada per Traugott (1993 i 1997) o Cornillie i Octavio (2015). Cal remarcar que ens referim en exclusiva a la realització de l'argument que fa el paper de tema (el mal, l'esdeveniment negatiu previst); no considerem, doncs, els arguments amb paper de beneficiari. Els tipus presents al corpus són: $\varnothing$, sintagma amb substantiu (N) com a nucli, clàusula introduïda per que, oració d'infinitiu (Vinf), gerundi (Vgerundi) i pronom. En aquesta anàlisi no prenem en consideració possibilitat que el $\mathrm{N}$ o Vinf aparega introduït per una preposició (aquest aspecte, i la variació diacrònica que presenta, ja s'ha tingut en compte en la descripció dels patrons sintàctics dels significats, §3.1). Per a il-lustrar la tipologia anterior, remetem a alguns dels exemples previs. En 2 trobem una mostra de realització absoluta del verb: «E s'í mostra la sua verga, ab què menassava als escolàs». En (15a) el tema es presenta com a SN amb un substantiu com a nucli: «li amenasà la pena rigurosa de la excomunió». En (19a) el tema es manifesta en el discurs en una subordinada introduïda per la conjunció que: «dit doctor Sabata amenasava que havia de matar a una cosina seua». Com a mostra d'oració d'infinitiu, remetem a l'exemple (21): «les gents d'armes stranyes que menassen de entrar». En (18) trobem una mostra de gerundi: «aquest testis menassà a la dita esclava fort dient-li que, si ella no li dehia què havia feta [de] la dita letra [...]». Finalment, trobem el tema pronominalitzat en (4): «e axí ho menassen que u faran tro lo dit greuge sia per justícia bé provehit».

La distribució d'aquests tipus segons el significat del verb apareix quantificada en la Taula 4 (s. XIII-1832) i en la Taula 5 (1832-1903).

Taula 4. Distribució del tipus de realització gramatical del tema segons els significats (s. XIII1832)

\begin{tabular}{|c|c|c|c|c|c|c|c|c|c|c|c|c|c|c|}
\hline \multirow{2}{*}{$S$} & \multicolumn{2}{|c|}{ Ø } & \multicolumn{2}{|c|}{$\mathbf{N}$} & \multicolumn{2}{|c|}{ que } & \multicolumn{2}{|c|}{ Vinf } & \multicolumn{2}{|c|}{ Vgerundi } & \multicolumn{2}{|c|}{ pronom } & \multicolumn{2}{|c|}{ total } \\
\hline & $f_{i}$ & $\%$ & $f_{i}$ & $\%$ & $f_{i}$ & $\%$ & $f_{i}$ & $\%$ & $f_{i}$ & $\%$ & $\mathrm{f}_{\mathrm{i}}$ & $\%$ & $f_{i}$ & $\%$ \\
\hline 1 & 83 & 51,2 & 7 & 4,3 & 43 & 26,5 & 18 & 11,1 & 10 & 6,2 & 1 & 0,6 & 162 & 100 \\
\hline 2 & 3 & 37,5 & 2 & 25 & 0 & 0 & 3 & 37,5 & 0 & 0 & 0 & 0 & 8 & 100 \\
\hline 3 & 19 & 90,5 & 2 & 9,5 & 0 & 0 & 0 & 0 & 0 & 0 & 0 & 0 & 21 & 100 \\
\hline 4 & 3 & 37,5 & 4 & 50 & 0 & 0 & 0 & 0 & 0 & 0 & 1 & 12,5 & 8 & 100 \\
\hline 5 & 0 & 0 & 8 & 100 & 0 & 0 & 0 & 0 & 0 & 0 & 0 & 0 & 8 & 100 \\
\hline 6 & 3 & 33,3 & 6 & 66,7 & 0 & 0 & 0 & 0 & 0 & 0 & 0 & 0 & 9 & 100 \\
\hline Total & 111 & 51,4 & 29 & 13,4 & 43 & 19,9 & 21 & 9,7 & 10 & 4,6 & 2 & 0,9 & 216 & 100 \\
\hline
\end{tabular}

Taula 5. Distribució del tipus de realització gramatical del tema segons els significats (18331903)

\begin{tabular}{|c|c|c|c|c|c|c|c|c|c|c|c|c|c|c|}
\hline \multirow{2}{*}{$S$} & \multicolumn{2}{|c|}{ Ø } & \multicolumn{2}{|c|}{$\mathbf{N}$} & \multicolumn{2}{|c|}{ que } & \multicolumn{2}{|c|}{ Vinf } & \multicolumn{2}{|c|}{ gerundi } & \multicolumn{2}{|c|}{ pronom } & \multicolumn{2}{|c|}{ Total } \\
\hline & $f_{i}$ & $\%$ & $\mathrm{f}_{\mathrm{i}}$ & $\%$ & $f_{i}$ & $\%$ & $\mathrm{f}_{\mathrm{i}}$ & $\%$ & $\mathrm{f}_{\mathrm{i}}$ & $\%$ & $f_{i}$ & $\%$ & $f_{i}$ & $\%$ \\
\hline 1 & 173 & 70,3 & 35 & 14,2 & 8 & 3,3 & 30 & 12,2 & 0 & 0,0 & 0 & 0,0 & 246 & 100,0 \\
\hline 2 & 20 & 62,5 & 5 & 15,6 & 0 & 0,0 & 7 & 21,9 & 0 & 0,0 & 0 & 0,0 & 32 & 100,0 \\
\hline 3 & 77 & 100,0 & 0 & 0,0 & 0 & 0,0 & 0 & 0,0 & 0 & 0,0 & 0 & 0,0 & 77 & 100,0 \\
\hline
\end{tabular}




\begin{tabular}{lcccccccccccccc}
4 & 1 & $\mathbf{2 5 , 0}$ & 2 & $\mathbf{5 0 , 0}$ & 0 & 0,0 & 0 & 0,0 & 0 & 0,0 & 1 & $\mathbf{2 5 , 0}$ & 4 & 100,0 \\
5 & 1 & $\mathbf{5 0 , 0}$ & 1 & $\mathbf{5 0 , 0}$ & 0 & 0,0 & 0 & 0,0 & 0 & 0,0 & 0 & 0,0 & 2 & 100,0 \\
6 & 6 & $\mathbf{1 5 , 4}$ & 13 & $\mathbf{3 3 , 3}$ & 0 & 0,0 & 20 & $\mathbf{5 1 , 3}$ & 0 & 0,0 & 0 & 0,0 & 39 & 100,0 \\
7 & 25 & $\mathbf{9 2 , 6}$ & 2 & $\mathbf{7 , 4}$ & 0 & 0,0 & 0 & 0,0 & 0 & 0,0 & 0 & 0,0 & 27 & 100,0 \\
8 & 0 & 0,0 & 4 & $\mathbf{1 3 , 3}$ & 0 & 0,0 & 26 & $\mathbf{8 6 , 7}$ & 0 & 0,0 & 0 & 0,0 & 30 & 100,0 \\
\hline Total & 303 & $\mathbf{6 6 , 3}$ & 62 & $\mathbf{1 3 , 6}$ & 8 & $\mathbf{1 , 8}$ & 83 & $\mathbf{1 8 , 2}$ & 0 & 0,0 & 1 & $\mathbf{0 , 2}$ & 457 & 100,0 \\
\hline
\end{tabular}

Amb el valor [S1], el verb pot seleccionar una major varietat de tipus gramaticals per a realitzar la funció de tema. És important remarcar que sols $\mathrm{amb}$ aquest significat el verb admet una subordinada introduïda per la conjunció que, la qual es vincula a aquest valor en tant que permet reportar de manera indirecta l'amenaça proferida pel $S$ agent. Tot i que menys nombrosa, la presència del gerundi també és exclusiva i significativa, en tant que hi trobem un verb de dicció introduint aquesta subordinada que parafraseja l'amenaça del S.

En cat. antic i modern, en els valors de caràcter [+subjectiu] ([S2]-[S6]), sols és possible realització absoluta del verb (excepte [S5]) i com a $\mathrm{N}$ del tema. Cal matisar que [S2], un significat de transició amb un valor [+subjectiu] i un $S$ [+agentiu], admet Vinf (no entrem a valorar el pes percentual per com és de reduïda la mostra). Cal apuntar també que en [S3] el tema (el mal) es realitza com a $S$ i, doncs, li correspon paper temàtic de causa; per aquesta raó, no es té en compte en aquesta descripció. Durant el s. XIX, destaca especialment l'atenció que la realització del tema com a Vinf és possible amb el significat nou [S8], i sobretot amb [S6], que en cat. modern sols admetia un $\mathrm{N}$ com a objecte. Aquestes tendències evolutives es descriuen amb més detall en la Taula 6 i en la Figura 4.

Taula 6. Evolució de la freqüència absoluta de la realització gramatical del tema (s. XIII-1903)

\begin{tabular}{|c|c|c|c|c|c|c|c|c|c|c|c|c|c|c|}
\hline \multirow{2}{*}{ Període } & \multicolumn{2}{|c|}{ ø } & \multicolumn{2}{|c|}{$\mathbf{N}$} & \multicolumn{2}{|c|}{ que } & \multicolumn{2}{|c|}{ Vinf } & \multicolumn{2}{|c|}{ gerundi } & \multicolumn{2}{|c|}{ pronom } & \multicolumn{2}{|c|}{ Total } \\
\hline & $f_{i}$ & $\%$ & $f_{i}$ & $\%$ & $f_{i}$ & $\%$ & $f_{i}$ & $\%$ & $\mathrm{fi}_{\mathrm{i}}$ & $\%$ & $\mathrm{f}_{\mathrm{i}}$ & $\%$ & $f_{i}$ & $\%$ \\
\hline s. XIII & 12 & 57,1 & 0 & 0,0 & 7 & 33,3 & 1 & 4,8 & 1 & 4,8 & 0 & 0,0 & 21 & 100,0 \\
\hline s. XIV & 16 & 64,0 & 2 & 8,0 & 3 & 12,0 & 3 & 12,0 & 1 & 4,0 & 0 & 0,0 & 25 & 100,0 \\
\hline s. XV & 16 & 53,3 & 1 & 3,3 & 8 & 26,7 & 2 & 6,7 & 2 & 6,7 & 1 & 3,3 & 30 & 100,0 \\
\hline s. XVI & 10 & 55,6 & 0 & 0,0 & 3 & 16,7 & 3 & 16,7 & 2 & 11,1 & 0 & 0,0 & 18 & 100,0 \\
\hline s. XVII & 21 & 35,6 & 11 & 18,6 & 19 & 32,2 & 3 & 5,1 & 4 & 6,8 & 1 & 1,7 & 59 & 100,0 \\
\hline s. XVIII & 32 & 61,5 & 10 & 19,2 & 2 & 3,8 & 8 & 15,4 & 0 & 0,0 & 0 & 0,0 & 52 & 100,0 \\
\hline $1800-1832$ & 5 & 45,5 & 5 & 45,5 & 1 & 9,1 & 0 & 0,0 & 0 & 0,0 & 0 & 0,0 & 11 & 100,0 \\
\hline $1833-1903$ & 303 & 66,3 & 62 & 13,6 & 8 & 1,8 & 83 & 18,2 & 0 & 0,0 & 1 & 0,2 & 457 & 100,0 \\
\hline Total & 112 & 51,9 & 29 & 13,4 & 43 & 19,9 & 20 & 9,3 & 10 & 4,6 & 2 & 0,9 & 216 & 100,0 \\
\hline
\end{tabular}


Figura 4. Evolució del pes percentual de la realització gramatical del tema (s. XIII-1903)

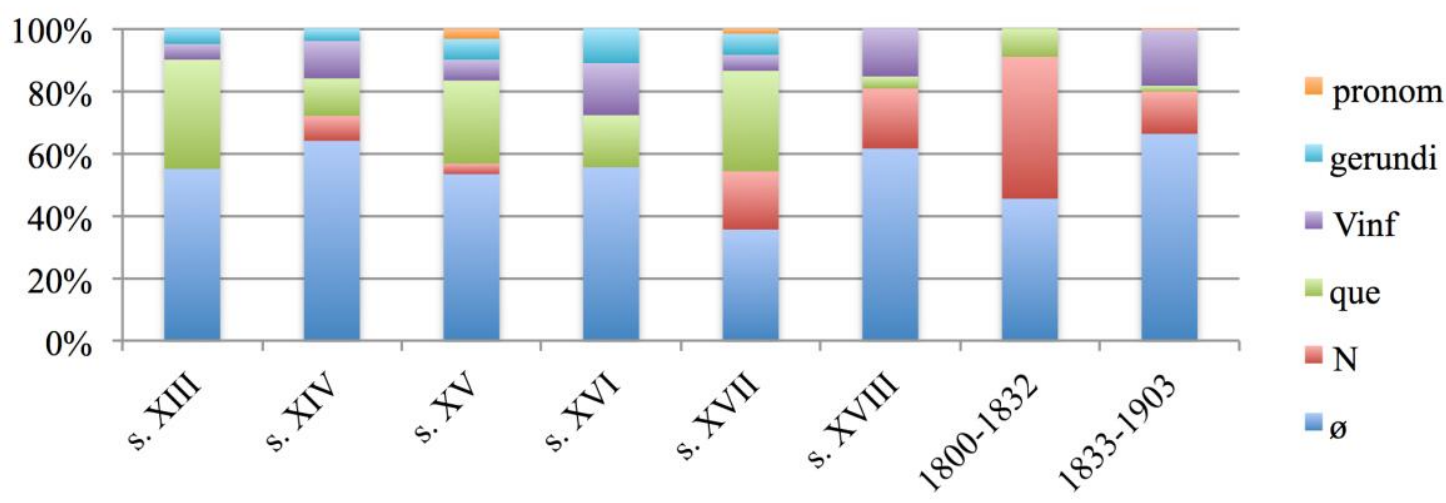

Tot i l'aparent variació que mostren les dades recollides en la Taula 6 i en la Figura 4, són significatius els fets següents: a) és constant al llarg de tot el període estudiat que la realització absoluta és majoritària (cat. antic: $57 \%$, cat. modern: 47,5 \%, 1833-1903: 45,5 \%, 1832-1903: 66,3\%). b) Decau en diacronia el pes de la clàusula introduïda per que (cat. antic: $22,6 \%$, cat. modern: $18 \%, 1833-$ 1903: 1,8 \%). c) En tercer lloc, s'observa com els casos en què el sintagma té com a nucli un $\mathrm{N}$ presenten el màxim en cat. modern $(21,3 \%)$, amb un creixement notable previ (partia d'un $3,2 \%$ en cat. antic) i un decaïment en cat. contemporani (fins al 13,4\%). d) Finalment, és notable l'increment percentual dels casos en què el verb introdueix una oració d'infinitiu en el període 18331903 (cat. antic: 9,7 \%, cat. modern: 9 \%, 1800-1832: 18,2 \%). Aquest increment no s'explica tant per l'expansió en [S1] (el percentatge és estable: 11,1 \% dels casos de [S1] en cat. antic i modern i 12,2 \% en cat. contemporani), com per la difusió en l'ús de [S6] (valor el patró del qual no admetia infinitiu en cat. antic i modern) i el significat nou [S8]. D'aquesta manera, si en cat. antic la major part dels casos de Vinf els trobem amb [S1] (85,7 \%) i secundàriament amb [S2] $(14,3 \%)$, en cat. contemporani el percentatge que correspon a [S1] es redueix al $36,14 \%$, mentre que l'ús en contextos subjectius és major: 63,86 \% ([S8]: 31,3\%, [S6]: 24,1 \% i [S2]: 8,4\%).

\subsection{Tipologia textual}

Una altra qüestió que ha estat rellevant per a explicar l'evolució del verb amenaçar és la tipologia textual en què s'han generat i difós els nous valors epistèmics. Cornillie i Octavio (2015) situen en la literatura humanística l'origen dels nous valors, com a calc del llatí. A l'hora d'analitzar aquesta variable, partim de les tipologies textuals que recull el CIGCMod (Antolí 2018)5 i analitzem

\footnotetext{
${ }^{5}$ Amb l'objectiu de poder comparar les dades del CIGCMod i del CTILC, hem referenciat les categories d'aquest segon corpus a les del cat. modern de la manera següent: la categoria «Obres religioses i morals» agrupa «Religió i teologia» i «Filosofia». «Textos literaris» agrupa els tipus «Narrativa», «Teatre», «Poesia» $\mathrm{i}$ «Assaig». «Textos historiogràfics, dietaris i epistolaris» agrupa «Correspondència», «Premsa» $\mathrm{i}$ «Història i Geografia. Biografia». La categoria «Textos
} 
la distribució dels casos i l'evolució d'aquesta. Es té en compte especialment la freqüència relativa del verb a fi de controlar la variació que resulta de treballar $\mathrm{amb}$ resultats de corpus diferents i en períodes en què sorgeixen i decauen algunes tipologies textuals.

Taula 4. Evolució de la freqüència relativa i absoluta del verb amenaçar en cat. modern i durant el s. XIX

\begin{tabular}{|c|c|c|c|c|c|c|c|c|c|c|}
\hline \multirow[t]{2}{*}{ Període } & \multicolumn{2}{|c|}{$\begin{array}{c}\text { Textos } \\
\text { juridicoadministratius } \\
\text { (Jur.) }\end{array}$} & \multicolumn{2}{|c|}{$\begin{array}{c}\text { Obres } \\
\text { religioses i } \\
\text { morals (Rel.) }\end{array}$} & \multicolumn{2}{|c|}{$\begin{array}{c}\text { Textos } \\
\text { literaris (Lit.) }\end{array}$} & \multicolumn{2}{|c|}{$\begin{array}{c}\text { Textos } \\
\text { historiogràfics, } \\
\text { dietaris i epistolaris } \\
\text { (Hist.) }\end{array}$} & \multicolumn{2}{|c|}{$\begin{array}{l}\text { Textos } \\
\text { cientificotècnics } \\
\text { (Cient.) }\end{array}$} \\
\hline & $\overline{f_{i}}$ & $\overline{h_{i}}$ & $\mathrm{fi}_{\mathrm{i}}$ & $\overline{h_{i}}$ & $f_{i}$ & $\overline{h_{i}}$ & $f_{i}$ & $h_{i}$ & $\mathrm{fi}_{\mathrm{i}}$ & $\mathbf{h}_{\mathrm{i}}$ \\
\hline Cat. modern & 31 & 0,000011 & 5 & 0,000056 & 18 & 0,000039 & 67 & 0,000024 & 1 & 0,000002 \\
\hline $1833-1903$ & 0 & 0 & 40 & 0,000055 & 280 & 0,000052 & 81 & 0,000077 & 56 & 0,000022 \\
\hline
\end{tabular}

Taula 5. Evolució de la freqüència relativa i absoluta dels valors epistèmics del verb amenaçar en cat. modern i durant el s. XIX

\begin{tabular}{|c|c|c|c|c|c|c|c|c|c|c|}
\hline \multirow[t]{2}{*}{ Període } & \multicolumn{2}{|c|}{$\begin{array}{c}\text { Textos } \\
\text { juridicoadministratius } \\
\text { (Jur.) }\end{array}$} & \multicolumn{2}{|c|}{$\begin{array}{c}\text { Obres } \\
\text { religioses i } \\
\text { morals (Rel.) }\end{array}$} & \multicolumn{2}{|c|}{$\begin{array}{c}\text { Textos } \\
\text { literaris (Lit.) }\end{array}$} & \multicolumn{2}{|c|}{$\begin{array}{c}\text { Textos } \\
\text { historiogràfics, } \\
\text { dietaris i epistolaris } \\
\text { (Hist.) }\end{array}$} & \multicolumn{2}{|c|}{$\begin{array}{l}\text { Textos } \\
\text { cientificotècnics } \\
\text { (Cient.) }\end{array}$} \\
\hline & $f_{i}$ & $h_{i}$ & $\mathrm{f}_{\mathrm{i}}$ & $h_{i}$ & $f_{i}$ & $h_{i}$ & $f_{i}$ & $h_{i}$ & $f_{i}$ & $h_{i}$ \\
\hline Cat. modern & 13 & 0,0000004 & 0 & 0 & 5 & 0,000010 & 33 & 0,000012 & 0 & 0 \\
\hline 1833-1903 & 0 & 0 & 20 & 0,000027 & 91 & 0,000017 & 54 & 0,000051 & 46 & 0,000018 \\
\hline
\end{tabular}

Si prenem les xifres absolutes, constatem que els usos epistèmics creixen de forma global, i passen a ser majoritaris durant el període 1833-1903 en Cient. (s. XIX: 82,14 \%), Hist. (cat. mod.: 49,25, s. XIX: 77,67), estan anivellats en Rel. (s. XIX: 50 \%) i no superen [S1] en Lit. (cat. mod.: 27,77, s. XIX: 32,5\%).

Més significativa és la freqüència relativa, que oscil·la poc entre el cat. modern i el s. XIX, amb un creixement moderat en el cas de les tipologies Lit. i Cient., estabilitat en el cas de Rel., i desaparició de dades en el cas de Jur. (fruit de la situació sociolingüística del cat. durant el s. XIX, que va ser prohibit en aquest àmbit). L'únic cas singular és el de Hist., tipologia en la qual passa del 0,000024 al 0,000077; com a resultat d'aquest creixement, passa a ser la tipologia en què el verb presenta una freqüència relativa major.

El que hem descrit de l'ús del verb en conjunt, es pot aplicar també a l'evolució dels valors epistèmics. Si bé observem un creixement en tots els casos (excepte Jur., pels motius exposats abans), la freqüència major és la de Hist. $(0,000051)$, seguida de Rel. $(0,000027)$.

De les dades anteriors podem concloure que, si bé els valors epistèmics s'estenen en totes les tipologies, l'expansió d'aquests significats es concentra especialment en la tipologia Hist., una tipologia que concentra gèneres textuals on predomina l'expressió d'una perspectiva personal, subjectiva, dels esdeveniments.

cientificotècnics» engloba «Ciències Socials», «Ciències Pures i Narturals», «Ciències Aplicades», «Belles Arts. Oci. Esports. Jocs» i «Llengua i Literatura». 


\section{DiscUSSIÓ}

Els resultats descrits en el punt anterior permeten esbossar una evolució del verb amenaçar ordenada en tres fases que coincideixen amb grans etapes de l'evolució de la llengua catalana: Fase 1. Català antic (s. XIII-XVI), Fase 2. Català modern (s. XVII-1832), Fase 3. Segle XIX (1833-1903). Aquesta classificació coincideix en bona mesura - també cronològicament - a la proposada per a l'anglès per Traugott $(1993,1994)$ i reformulada per a les llengües europees per Heine i Kuteva (2006).

\section{Fase 1. Català antic (s. XIII-XVI)}

El verb amenaçar (o menaçar, en cat. antic ${ }^{6}$ ) es testimonia en cat. des dels primers textos (primera meitat del s. XIII, a les Homilies d'Organyà). És competidor de la solució perifràstica fer amenaces, habitual en la llengua antiga i moderna (c.f. CIGCA, CIGCMod): «Grans menasses e grans morts ferà a aquells qui no'l creuràn» (R. Llull, Doctrina Pueril; apud DCVB, s.v. amenaçar); amb aquesta comparteix inicialment el significat i el règim argumental: [S1] 'Anunciar [a algú que està en disposició de fer o no fer una cosa] 2 [un mal, un càstig] 3 com a conseqüència', en una construcció intransitiva (serà així durant tot el període antic majoritàriament) amb S/A, datiu amb paper de beneficiari i un complement preposicional que introdueix el tema (a més de possibles adjunts). És el mateix valor que trobem en el castellà (Cornillie i Octavio 2015), en l'anglès (Traugott 1993) o en l'alemany (Heine i Kuteva 2006) coetanis. També és la situació que trobem en francés antic (DÉCT, s.v. menacier; DGodefroy, s.v. menacier).

Aquesta caracterització del verb devia ser pròpia també del cat. preliterari, i així es manifesta en el llatí medieval català (CODOLCAT; vegeu-ne, com a mostra, l'exemple 22).

(22) In super etiam iudicaverunt ut Geraldus, filius Bernardi, qui menaciavit ante iam dictum comitem quod ad suum hominem tolleret pedem, ut iuret predictus Geraldus quod non menaciauit, aut iuret, si hoc dixit, quod ita dixit sicut follis. (AComtalPerg II [XI], 321; CODOLCAT)

${ }^{6}$ Quant a l'alternança entre la forma etimològica menaçar i la prefixada amenaçar, cal tenir en compte que la primera és majoritària en català antic i clàssic, com ja ho apuntà Coromines (DECat, s.v. menaça, 568b, 18-32). De fet, la solució prefixada la testimoniem per primera vegada durant el s. XIVb, en un text mallorquí, però serà residual fins al s. XVIb (s. XIV: $4 \%$, s. XV: 3,3\%, s. XVI: $50 \%$ ). Des de llavors, la situació es capgira ràpidament (s. XVII: 98,3\%, s. XVIII: 92,3\%, 1800-1832: 100 \%). En l'expansió de la forma prefixada no observem pautes de tipus diatòpic o semàntiques, i si bé no aprofundirem en el motiu d'aquest canvi, sí que volem fer notar que la solució prefixada és anterior i s'estén molt més ràpidament en espanyol (c.f. CNDHE). De fet, el català confluirà, d'aquesta manera, amb les llengües iberoromàniques, ja que tant l'aragonés (amenasá), l'asturià (amenazar), el castellà (amenazar) i el portugués (ameaçar) contemporanis presenten la forma prefixada; i això a diferència de l'italià (minacciare) o el francès (menacer). 
En aquest context (remetem, de nou, als exemples 1-3), el L descriu l'esdeveniment pel qual un S/A, generalment [+humà] (o un ésser o entitat personificats, com en l'exemple 16) i dotat de voluntat, expressa el compromís condicionat de dur a terme en el futur una determinada acció per a perjudicar algú, sovint present en l'acte. Es tracta d'un valor que hem definit com a [+agentiu] i [-subjectiu], i que integra la noció de futur (en tant que expressa una intenció).

Això no obstant, observem que, juntament amb el nucli semàntic prototípic, hi ha un seguit de contextos en què aquest caràcter [+agentiu] i [-subjectiu] es troba atenuat. D'aquesta manera, el 74,2 \% del total dels exemples del cat. antic s'ajusten a una definició prototípica d'acord amb el criteri de [+agentivitat], mentre que en un 22,6\% de la mostra l'agentivitat del S s'ha de matisar atenent un seguit de factors (diacrònicament: $a$ ) si és un $S$ col-lectiu, b) un ésser sobrenatural, c) si s'expressa la intenció de manera mediata, d) si el S és omés, e) si és una personificació). De la mateixa manera, quant al tret [-subjectiu], els casos s'ajusten al prototip de [S1] en un percentatge similar en cat. antic $(67,7 \%)$, mentre que en un $25,8 \%$ de la mostra total del període, aquest tret es troba atenuat i es presenta una situació més abstracta i durativa.

Els casos en què s'atenua el caràcter [+agentiu] i/o [-subjectiu] del verb (un quart de la mostra en cat. antic) constitueixen una frontera difusa, un context pont que podria haver donat lloc, durant els s. XV i XVI, a [S2] 'Estar a punt d'infligir [un mal]2 [a algú, a alguna cosa]' (amb un S/A atenuat, i [+subjectiu]). La inferència invitada que permet el pas d'aquests contextos pont a [S2] es podria formalitzar de la manera següent: +[ALGÚ TÉ EL COMPROMÍS DE FER ALGUNA COSA EN EL FUTUR] $\rightarrow$ [ÉS POSSIBLE QUE ALGÚ FAÇA ALGUNA COSA EN EL FUTUR]+. D'aquesta manera, persisteix la noció de futur i l'avaluació negativa de l'esdeveniment previst, mentre que s'esvaeix la intencionalitat de l'agent (la voluntat del qual coneixem per la interpretació que en fa el L/C) i es fa abstracta la situació descrita pel verb, que ara descriu un estat de coses avaluat pel L/C més que no un esdeveniment.

(23) [...] lo turch està a la porta menasant-nos a Itàlia, ý los lluterans tenen ocupada quasi tota Alemanya ý França; tenim ya si és perduda Grèsia; Inglaterra ya veu qual està [...]. (Cristòfor Despuig, Los col-loquis de la insigne ciutat de Tortosa [XVI], 71, 11; CIGCMod)

Més enllà dels exemples corresponents a [S1] i [S2], durant aquest període són molt pocs els casos que difereixen d'aquesta caracterització (4,3\% del total; Taula 1) i que trenquen amb el caràcter gradual del procés de subjectivació que comença a apuntar-se en cat. antic. Són exemples que trobem en traduccions del llatí (en la traducció catalana del s. XIV dels Diàlegs de sant Gregori; exemple 24a) o en obres de prosa literària (Tirant lo Blanch, exemple 24b; Curial e Güelfa, exemple 24c), en aquest darrer cas, en contextos dotats d'un gran dramatisme. En uns casos i en els altres, es tracta de calcs del llatí o de l'italià: 
(24) a. E $\cdot I \cdot$ dia, per colpa de nocura, a la dita ciutat d'Ancona se mès foc, e con cremàs fortment, corregren totz, que apagassen lo foc; e aquels gitan ayga a folcatz, axí crexia la flama que ja paria que manaçàs lo destruïment de tota la ciutat. (Gregori el Gran, Diàlegs [St. Gregori] [XIV], Fol. $8 \mathrm{v}, \quad 1 . \quad 11$ ) Cumque vehementer arderet, concurrerunt omnes ut ignem exstinguerent. Sed illis aquam certatim projicientibus, ita crescebat flamma, ut jam totius urbis $[\mathrm{H}]$ interitum minari videretur. (Gregori el Gran, Sancti Gregorii Papae Dialogorum [VI], Libri IV, Caput VI; Patrologia Latina Database)

b. $\quad i$ E no veus tu lo cel ple de tenebres qui contínuament nos menaça diversitat de temps, ço és, mortalitats a la terra, ab neus, aygües, trons e lamps spantables? (Joanot Martorell, Tirant lo Blanch [XV], 1201, 7; CIGCA) Non vedi tu il cielo pieno d'oscurità, continuo minacciante gravissime pestilenze alla terra con acque, con nevi, con venti e con ispaventevoli tuoni? (Giovanni Boccaccio, $\mathrm{La}$ Fiammetta; apud Pujol, 96 )

c.Curial: -A Melchior, pare meu! Prech-te, si ésser pot, que cerchs altra via a ma consolació, e, ab los ulls de la pensa, mira la color del meu cor. Vet la mort que.m menaça, cuydant-se que yo la tema [...]. (Enyego d'Àvalos [?], Curial e Güelfa [Xv], 268, 18; CIGCA)

En el cas de (24b), la intertextualitat entre el fragment de la Fiammeta i la del Tirant l'apuntà Pujol (1998: 96). En el cas de l'exemple (24c), en un altre lloc (Antolí, en premsa) ja vam argumentar, partint de la col·locació la color del cor, que es tractava d'una possible calc de l'italià; aquesta possibilitat és coherent amb la hipòtesi sobre l'autoria de l'obra formulada per Soler (2017) i amb la caracterització lingüística de l'obra feta per Martines (2012). Aquests calcs i intertextualitats són similars als que testimonien Cornillie i Octavio (2015) en espanyol, en exemples del s. XV, que trenquen amb el concepte de canvi gradual.

\section{Fase 2. Català modern}

En cat. modern observem que s'inicia l'expansió en l'ús del verb (amb una freqüència relativa en augment: s. XIII: 0,000020, s. XIV: 0,000011, s. XV: 0,000008, s. XVI: 0,000011, s. XVII: 0,000018, s. XVIII: 0,000018, 1800-1832: 0,000038, 18321903: 0,000058). Aquesta expansió s'explica pel sorgiment de nous valors de caràcter epistèmic, subjectius, mentre que la freqüència relativa de [S1] oscil·la poc (amb un valor per al període de 0,0000117). La cronologia és similar a la de les altres llengües europees estudiades (Heine i Kuteva 2006).

El pas de [S1] als significats qualificats d'epistèmics serà possible a partir de [S2], que funciona com a context pont en tant que combina una avaluació subjectiva per part del L/C amb la necessitat d'un $S$ [+agent] que realitze el mal previst. A partir de [S2], és possible la inferència +[ÉS POSSIBLE QUE ALGÚ FAÇA ALGUNA COSA EN EL FUTUR] $\rightarrow$ [ÉS POSSIBLE QUE OCÓRREGA UN MAL EN EL FUTUR]+. Aquesta inferència contextual comportarà la desaparició de la restricció semàntica per la qual el verb selecciona un $S$ [+agent], la qual cosa es manifesta en el corpus en la possibilitat de trobar el verb realitzat com a impersonal ([S5] 
'Presentar-se [un perill, un mal] $]_{1}$ [a algú $]_{2}$ com a probable', 8,5\% de la mostra en el s. XVII; exemple 25) o amb el tema ara realitzat com a $S$ ([S3] '[Un perill, un mal] ${ }_{1}$ presentar-se [a algú, alguna cosa $]_{2}$ com a probable', 11,9\% de la mostra en el s. XVII; exemples 6a i 6b).

(25) Dilluns a XX de dit los srs. conçallers se n'anaren a la Isglésia del monestir de las maras Caputxinas [...] y allà tingueran serca de una ora oratió perquè Nostre Sr. nos deslliuràs de las tres plagas sens amanaçavan com són guerra, fam y pesta [...]. (Manual de Novells Ardits [XVII], 45, 28; CIGCMod)

Des de la perspectiva semàntica, doncs, el verb deixa d'expressar la intenció del S/A, i pren en canvi un valor modal epistèmic, en tant que es tracta d'una predicció. Heine i Kuteva (2006) assenyalaren que aquest valor epistèmic va lligat, en el cas de amenaçar, als components següents: avaluació negativa, component aspectual en tant que implica un canvi d'estat i valor temporal de futur. A aquestes nocions cal afegir, en tant que és significatiu en l'evolució posterior del verb, el component evidencial, que es pot inferir del fet que el verb expressa una predicció (en aquest sentit, l'evolució és similar a la del verb voler amb valor epistèmic/evidencial; vegeu Antolí 2015c; en aquest mateix sentit, quant al sorgiment del valor epistèmic/evidencial del futur i del condicional en català, vegeu Martines 2017a, 2017b, 2018).

Cal remarcar que l'aparició i l'expansió d'aquests significats més subjectius en cat. modern no és sobtada, sinó gradual. Això es manifesta en diversos fets: a) l'expansió dels nous valors és progressiva (la suma de [S3], [S5] i [S6] representa, en el s. XVII: 22,1 \%, s. XVIII: 34,6 \%, 1800-1832: 45,5\%); b) l'aparició de la solució impersonal [S5] es pot entendre com una transició entre [S2], d'una banda, i [S3] i [S6] de l'altra, la qual cosa explica el sorgiment i l'immediat decreixement d'aquest valor (s. XVII: 8,5 \%, s. XVIII: 5,8 \%, 1800-1832: $0 \%)$. I c) en gairebé la meitat de la mostra dels casos classificats com a [-agentiu] en cat. modern, aquest tret es troba atenuat pel fet que la realització de l'estat de coses futur presentat com a possible pel verb implica un agent (segons s'ha argumentat en 3.2 i consta en la Taula 2).

Finalment, l'aparició de [S6] '[Un estat de coses] donar senyals d'estar a punt d'ocórrer [un esdeveniment advers]2' en el s. XVII i l'expansió durant el s. XVIII podria entendre's com una passa més en aquest procés de subjectivació. Més en concret, podria derivar de contextos en què [S3] i [S5] presenten un $S$ [-agentiu] no atenuat, els quals es caracteritzen perquè: $a$ ) la predicció del $\mathrm{L} / \mathrm{C}$ es fonamenta en uns indicis (concretament, una aparença) dels quals L té coneixement directe; i b) l'assoliment de la situació prevista és independent de la voluntat d'un agent que puga controlar-ne la realització, i es considera el resultat natural a la tendència observada.

D'aquesta manera, i en el sentit que apunta Traugott (1997: 190) quan es refereix a la dimensió inferencial del valor epistèmic de threaten, la inferència invitada que podria haver fet possible l'evolució és +[L EXPRESSA QUE ÉS POSSIBLE 
QUE OCÓRREGA UN MAL EN EL FUTUR] $\rightarrow$ [L DISPOSA D'INDICIS QUE OCORRERÀ UN MAL EN EL FUTUR]+, és a dir: si el L expressa que un mal és possible, dona a entendre que hi ha indicis que fonamenten aquesta possibilitat. Cal remarcar el fet que en [S6], si bé es mantenen els components epistèmic i de futur que trobàvem en els significats anteriors, es focalitza el valor evidencial des del moment que el S explicita, en l'oració, l'estat de coses (els indicis) que fonamenten la predicció, en la línia del que ja vam argumentar en el cas de la perífrasi [voler Vinf] (Antolí 2015c).

Això no obstant, si bé és plausible aquesta explicació, en el cas de la locució amenaça ruïna (i derivats) concloem que és un calc del llatí en tant que la locució minantur ruina és habitual en textos legals catalans escrits en llatí a partir dels Furs de la ciutat de València (26a) i dels Costums de la ciutat de Tortosa (26b).

(26) a. Si domus vicini minentur ruinam, ita quod ex illa ruina possit vicino in domibus suis damptnum conting[er]e, vicinus domos suas ruinosas fulciere teneatur vel vicino cautionem prestare de dampno illi futuro, si forsam ex ruina illa dampnum sibi contingeret. (Fori Regni Valentiae; apud Pacheco 1995)

b. Si paretz o cases d' alcun o cuberta de cases o murs de la ciutat minantur ruina, so és que volen caure o estan en reech de caure, a coneguda d' uns e d' altres aquel qui a temor que càgia, ven e deu venir a la cort, e aquí mostrar com aqueles paretz, cases o cuberta o murs minantur ruina, e que seria gran dan d'él e d'altres [...]. Con sia desús dit que si cases d'alcun veyn minantur ruinam, so és que si les dites cases volen caure e que sien en rech de caure [...] per sentència dels ciutadans coven que.l demanat dón fermansa, mal son grat, al demanador, que si dón vènia al demanador que lo y emén e lo y refassa, o que derroch la paret o cuberta o alò que vol caure e don pot donar; e assò és electió del demanador, qual que.n vula demanar: o la fermansa, o el derrocar, o l'adobar si adobar se pot e lo demanat ha de què u pusca adobar. (Costums de Tortosa [XIIIb], 166; CIGCA)

Com s'observa en els exemples anteriors, i especialment en (26b), la locució constitueix una unitat terminològica del dret que descriu un supòsit legal amb unes servituds associades (vegeu-ne la descripció que en fa Pacheco 1995). Aquest terme, que trobem originalment en llatí, es trasllada al català amb solucions diverses: amb l'auxiliar voler (Antolí 2015c) més antigament, i des del s. XVII també amb amenaçar, primer amb un $\mathrm{N}$ (exemple 9b), com en llatí, per a expressar el tema i tardanament (s. XIX) amb un Vinf. Aquesta hipòtesi, a més, permet explicar que: a) trobem el primer exemple isolat de la loc. amenaça rü̈na durant la primera meitat del s. XVII, abans que els contextos pont previstos; $b$ ) que el verb se sature amb el susbstantiu rü̈na i s'especialitze en general amb el perill de caiguda d'un element constructiu. c) La perífrasi [voler Vinf] se satura des del s. XIII amb el substantiu ruina i, més tardanament, amb els infinitius ploure o caure amb un valor epistèmic/evidencial des d'època moderna (s. XVII i XVIII), paral·lelament al cas del verb amenaçar (Antolí 2015c).

En resum, i si bé no podem concloure que el valor epistèmic és una interferència del llatí, com apunten Cornillie i Octavio (2015), sí que constatem 
que la locució amenaça ruina i la derivada amenaça de caure (i variants) resulten de la interferència d'aquesta llengua.

\section{Fase 3. Català contemporani (1833-1903)}

Durant el s. XIX el verb assoleix la caracterització que trobem en la llengua contemporània (recollida al DDLC, s.v. amenaçar), amb dos grans nuclis semàntics amb un pes similar: el primer identificat amb [S1], un ús [+agentiu] i [-subjectiu]; i el segon integrat per una constel-lació de significats i sentits ([S2]-[S8]) que coincideixen a presentar (amb graus diversos) un valor epistèmic, [-agentiu] i [+subjectiu]. A [S1] correspon un 53,9\% dels casos durant el període, mentre que els significats més subjectius representen el $46,1 \%$ restant.

En aquesta etapa observem dues novetats importants: en primer lloc, l'aparició (ja en la dècada dels anys 30 del s. XIX) de dos nous significats que comparteixen el fet que situen la causa de l'amenaça com a S: [S7] '[Alguna cosa] ${ }_{1}$ constituir un risc de dany per a [algú, alguna cosa]2' i [S8] '[Alguna cosa]1 donar motius per a témer [un perill, un mal] ${ }^{\prime}$. És significatiu perquè fins ara, el procés de subjectivació descrit pel verb havia comportat la dissolució del S en construccions impersonals ([S5]) o en un estat de coses (com en [S6]), o que el tema de S1 -el perill, el mal previst - fos elevat a la categoria de S ([S3]). El valor [S7] podria haver derivat dels significats epistèmics previs, a partir dels contextos de caràcter [-agentiu] no atenuat. En concret, la inferència que podria haver fonamentat el pas d'aquells contextos a aquests altres és: +[ALGUNA COSA ÉS A PUNT D’INFLIGIR UN MAL A ALGÚ O ALGUNA COSA] $\rightarrow$ [ALGUNA COSA ÉS UN PERILL PER A ALGÚ O ALGUNA COSA]+. Per la seua banda, [S8] és un significat molt proper (formalment i semàntica) a [S2] i [S6], amb la diferència que ara se situa la causa com a $S$.

El segon canvi que s'esdevé durant el s. XIX és l'alteració del tipus de realització gramatical del tema. Així, doncs, a) decau el pes de la clàusula introduïda per que, la qual es vincula a [S1] i, doncs, perd pes percentual en paral-lel al significat a què s'associa. $b$ ) En segon lloc, l'expansió en cat. modern i decreixement en cat. contemporani del pes dels casos que tenen un $\mathrm{N}$ com a nucli del sintagma que expressa el tema també s'explica per l'evolució semàntica del verb. Aquest tipus de realització es vincula als usos epistèmics del verb més que no als de caràcter [-subjectiu], la qual cosa explica la poca presència en cat. antic i posterior expansió en cat. modern. Ara bé, aquest tipus es veurà desplaçat per l'expansió de l'infinitiu en aquests contextos en cat. contemporani, concretament en [S6] i amb l'aparició de significats com [S8] en què es prefereix l'oració d'infinitiu. c) Finalment, el tret més interessant és, potser, el notable increment percentual dels casos en què el verb introdueix una oració d'infinitiu en el període 1833-1903. Aquesta solució és antiga, però es mostra estable en el període s. XIII-1832 (al voltant del $9 \%$ del total dels casos); 
en canvi, en cat. contemporani arriba al 18,2 \%. Aquesta expansió no s'explica per un augment en l'ús dels valors amb què apareix en la llengua antiga i moderna ([S1] i [S2]), sinó per la difusió del Vinf en contextos epistèmics, ja que penetra en [S6] i apareix amb el nou valor [S8], en el qual és majoritària. Les dades de què disposem en aquest estudi no són suficients per a explicar aquesta expansió de l'infinitiu; per a trobar la resposta caldria pensar, potser, més que no en una evolució espontània del cat., en una interferència del castellà, llengua en la qual l'expansió de l'infinitiu és anterior (Cornillie i Octavio 2015).

En el cas de [S6], observem, a més del canvi del patró sintàctic, una lleugera diversificació semàntica en el tipus de tema que admet. Si bé la major part de la mostra correspon als contextos inicials (la imminència de l'ensorrament d'un element constructiu, 46,2 \% dels casos; o d'un fenomen meteorològic advers, 35,9\%), constatem una certa presència d'altres contextos nous $(17,9 \%)$ en els exemples més tardans (finals del s. XIX), i fonamentalment verbs d'acció o de canvi d'estat (en paral-lel a la situació que troba Cornillie 2007 en espanyol contemporani). Cal fer notar també que si bé en cat. modern el verb colloca fonamentalment amb ruina i pluja, ara s'observa una major diversitat en els infinitius (caure, derrumbar-se, desaparéixer, desplomar-se, esfondrar-se, esllavissar-se) i substantius admesos (borrasca, gelada, nevada, tempestat, temporal, etc.).

D'acord amb el que hem vist, l'expansió d'aquests valors epistèmics i evidencial no s'esdevé en totes les tipologies textuals estudiades per igual, sinó que el creixement s'observa d'una manera molt marcada en els textos de la tipologia que hem definit com a Textos historiogràfics, dietaris i epistolaris; aquesta tipologia concentra la correspondència, la premsa, els textos historiogràfics i els dietaris personals. Això és coherent amb el fet que es tracta d'uns gèneres més proclius a l'expressió personal de l'autor, de la seua subjectivitat. Si efectivament l'expansió dels usos epistèmics i evidencial (especialment [S6], [S7] i [S8]) s'explica com a interferència de l'espanyol, podem concloure que es tracta d'una interferència localitzada especialment en aquests gèneres textuals.

\section{CONCLUSIONS}

L'evolució del verb amenaçar en català segueix un procés de gramaticalització que s'ajusta, a grans trets, amb la proposta d'E. C. Traugott $(1993,1997)$, el qual es caracteritza semànticament per la subjectivació progressiva del verb, en tant que el significat tendeix a basar-se gradualment en la creença subjectiva del parlant sobre la proposició.

L'evolució es pot estructurar en tres fases que coincideixen amb les grans etapes de l'evolució de la llengua catalana: Fase 1. Català antic (s. XIII-XVI), Fase

2. Català modern (s. XVII-1832), Fase 3. Segle XIX (1833-1903). Aquesta classificació coincideix en bona mesura -també cronològicament- a la 
proposada per a l'anglès per Traugott (1993, 1994) i reformulada per a les llengües europees per Heine i Kuteva (2006). Fase 1: en cat. antic trobem el verb amb [S1], denota un acte de parla pel qual el $S$ es compromet de forma condicionada a dur a terme una acció en contra d'algú, generalment present a l'acte. Es tracta d'un verb [+agentiu] i [-subjectiu], que es realitza en una construcció absoluta o que selecciona un argument amb funció de tema, concretament una completiva introduïda per que o una oració d'infinitiu. Secundàriament trobem alguns casos de [S2], en els quals el S continua sent agent, però la situació descrita es defineix per ser subjectiva. Fase 2: en cat. modern es despleguen els valors epistèmics: [S2]-[S5], i l'epistèmic-evidencial: [S6] amb complement nominal. Aquests significats coincideixen a descriure una predicció del L, i no la intenció del S. Aquest desplegament va de la mà de l'expansió del N com a nucli del sintagma que expressa el tema. Fase 3: en el període 1833-1903 observem la consolidació de dos nuclis semàntics amb un pes similar (al voltant de la meitat de la mostra), el significat lèxic ([S1]) i l'epistèmic/evidencial ([S2-S8]), amb l'aparició de dos nous significats epistèmics ([S7] i [S8]). El fet més significatiu és l'expansió de l'oració d'infinitiu per a expressar el tema, amb [S6] i [S8], de manera que és en aquest moment quan trobem els primers casos assimilables al concepte d'auxiliar evidencial proposat per Cornillie.

Aquest procés de subjectivació creixent es pot explicar com a resultat de la codificació d'implicatures conversacionals ( $d$ 'acord amb la IITSC de Traugott 2012), d'acord amb les dades de corpus de què disposem. Això no obstant, el procés no es pot explicar simplement com una evolució interna del català, aïllat de les llengües de l'entorn. Les dades conviden a matisar la proposta de Traugott, en la línia del que proposen Heine i Kuteva (2006), i especialment Cornillie i Octavio (2015). No es pot obviar la dimensió cultural del canvi lexicosemàntic.

L'evolució del verb amenaçar en català no s'esdevé de forma aïllada, sinó que es troba condicionada per les llengües amb què entra en contacte (cat. antic: llatí i italià, cat. modern: llatí i espanyol; cat. contemporani: espanyol). En aquest sentit, cal diferenciar entre el calc propi d'una traducció o d'una intertextualitat; i la interferència naturalitzada en el codi lingüístic. En cat. antic, especialment durant els s. XIV-XVII, trobem un seguit d'exemples que identifiquem clarament $a \mathrm{mb}$ calcs de l'italià o del llatí, en traduccions o intertextualitats. Són exemples fàcils de detectar en tant que trenquen amb la gradualitat del canvi semàntic esperable, i a la vista de la tendència observada no arriben a condicionar l'evolució del verb amenaçar. En segon lloc, han estat identificats alguns usos que podrien estar interferits pel llatí i que podrien donar lloc en cat. modern a [S6], en concret, a la locució en cat. amenaçar ruïna i derivats; aquesta mateixa construcció la retrobem en documentació legal valenciana i catalana escrita en llatí des del s. XIII. També hem apuntat que el triomf de la forma prefixada amenaçar és coherent amb la realitat de les llengües 
peninsulars i, en concret, el castellà. En tercer lloc, durant el s. XIX, observem la difusió sobtada d'uns nous significats epistèmics ([S7] i [S8]) i la preferència de l'infinitiu per a expressar el tema; suggerim que aquest canvi podria estar condicionat per l'espanyol, a la vista dels estudis que s'han fet sobre el tema en aquella llengua.

Finalment, és important remarcar que l'expansió dels valors epistèmics i evidencial susceptibles d'estar interferits pel castellà durant el s. XIX es concentra especialment en un grup de gèneres textuals (la correspondència, la premsa, els textos historiogràfics i els dietaris personals) caracteritzats per una major subjectivitat, és a dir, d'expressió personal de l'autor.

BIBLIOGRAFÍA

ANTOlí MARTíneZ, J. M. (2015a), L'evidencialitat en català antic: estudi de corpus i acostament segons la gramàtica cognitiva, tesi doctoral, Alacant, Universitat d'Alacant. Disponible a: <http://rua.ua.es/dspace/handle/10045/51070>.

ANTOLÍ MARTínEZ, J. M. (2015b), «The rise of an inferential evidential in medieval Catalan: The verb témer between the XIII and XV centuries», eHumanista/IVITRA, 8, 342-361.

ANTOlí MartíneZ, J. M. (2015c), «Voler + infinitive in Catalan: From the imminence aspectual periphrasis to the epistemic and evidential marker (from the 13th century to the present day)», Catalan Journal of Linguistics, 14, 11-31.

ANTOLÍ MARTÍNEZ, J. M. (2018), «El procés de constitució del Corpus Informatitzat de la Gramàtica del Català Modern (CIGCMod). Objectius, criteris i avaluació», Notandum, 48, 3-20.

ANTOLÍ MARTíneZ, J. M. (en premsa), «Observacions sobre l'expressió dels sentiments en el Curial e Güelfa», en Estudis lingüístics $i$ culturals sobre Curial e Gü̈lfa, Ferrando, A. (ed.), Amsterdam, John Benjamins.

BEL, A. (2002), «Les funcions sintàctiques», en Gramàtica del català contemporani, Solà, J., Lloret, M. R., Mascaró, J. i Pérez Saldanya, M. (eds.), Barcelona, Empúries, 10771150.

CIGCA = MARTINES, J. I MARTINES, V. (dirs.), Corpus Informatitzat de la Gramàtica del Català Antic, Alacant, ISIC-IVITRA (Universitat d'Alacant).

CigCMod = MARTINeS, J., MARTINES, V. I PÉREZ-SAldANYA, M. (dirs.), Corpus Informatitzat de la Gramàtica del Català Modern, Alacant, ISIC-IVITRA (Universitat d'Alacant).

CODOLCAT = QUETGlas NiCOLAU, P. J. (dir.) (2013), Corpus Documentale Latinum Cataloniae, Barcelona, Institució Milà i Fontanals.

COMPANY COMPANY, C. (2004), «Gramaticalización por subjetivización como prescindibilidad de la sintaxis», Nueva Revista de Filología Hispánica, 52(1), 1-27.

CORNILLIE, B. (2005), «Agentivity and subjectivity with Spanish prometer 'to promise' and amenazar 'to threaten'. A study of constructional and diatopical variation», Revista Internacional de Lingüística Iberoamericana, 3(1), 171-196.

CoRnillie, B. (2006), "A Paradigmatic View of Spanish amenazar 'to threaten' and prometer 'to promise'», Folia Linguistica, 39(3-4), 385-415. 
CORNILliE, B. (2007), Evidentiality and Epistemic Modality in Spanish (Semi)Auxiliaries, Berlín-Nova York, Mouton de Gruyter.

CORNILliE, B. (2016), «Los auxiliares evidenciales en español», en La evidencialidad en español: teoría y descripción, González Ruiz, R., Izquierdo Alegría, D. i Loureda Lamas, Ó. (eds.), Madrid-Frankfurt am Mein, Editorial Vervuert-Iberoamericana, 227-250.

Cornillie, B. I Octavio DE TOledo y HuertA, Á. S. (2015), «The diachrony of subjective amenazar 'threaten'», en New Directions in Grammaticalization Research, Smith, A., Trousdale, G. i Waltereit, R. (eds.), Amsterdam-Philadelphia, John Benjamins, 187-208.

CTILC = RAFEL, J. (dir.), Corpus Textual Informatitzat de la Llengua Catalana [en línia]. Barcelona: Institut d'Estudis Catalans, 2005 [Consulta: gener 2019]. Disponible a: $<$ http://ctilc.iec.cat/>.

DAcadémie = ATILF I ACADÉMIE FRANÇAISE. Dictionnaire de l'Académie française, neuvième édition [en línia]. París: ATILF-Académie Française, 2007 [Consulta: gener 2019]. Disponible a: <http://atilf.atilf.fr/academie9.htm>.

DAguiló = AGUILÓ I FUSTER, M. (1914-1934), Diccionari Aguiló, Barcelona, Institut $\mathrm{d}^{\prime}$ Estudis Catalans.

DALLA = ACADEMIA DE LA LLINGUA ASTURIANA, Diccionariu de la Llingua Asturiana [en línia]. Uviéu: Academia de la Llingua Asturiana, 2000 [Consulta: gener 2019]. Disponible a: $<$ http://www.academiadelallingua.com/diccionariu/>.

DCVB = AlCOVER, A. M. I MOLL, F. de B. (1985), Diccionari Català-Valencià-Balear, Palma de Mallorca, Moll.

DDLC = RAFEL, J. (dir.). Diccionari descriptiu de la llengua catalana [en línia]. Barcelona: Institut d'Estudis Catalans, 1985 [Consulta: gener-abril 2019]. Disponible a: $<$ http://dcc.iec.cat/ddlc/index.asp >.

DECat = COROMINES, J. (1995), Diccionari etimològic i complementari de la llengua catalana, Barcelona, Curial Edicions Catalanes-La Caixa.

DIEC2 = INSTITUT D'ESTUDIS CATALANS (IEC) (2007), Diccionari de la Llengua Catalana, Barcelona, Edicions 62-Enciclopèdia Catalana.

DIEWALD, G. I SMIRNOVA, E. (2010), «Evidentiality in European languages: the lexicalgrammatical distinction», en Linguistic Realization of Evidentiality in European Languages, Diewald, G. i Smirnova, E. (eds.), Berlin-Nova York, Walter de Gruyter, 279-308.

DLabèrnia = LABÈRNIA, P. (1839), Diccionari de la llengua catalana, Barcelona, Estampa dels Hereus de la Vda. Pla.

DMoliner = MOLINER, M. (2002), Diccionario del uso del español, Madrid, Gredos.

Heine, B. I Kuteva, T. (eds.) (2002), World Lexicon of Grammaticalization, Cambrigde, Cambridge University Press.

KISSINE, M. (2010), «Metaphorical projection, subjectification and English Speech Act verbs», Folia Linguistica, 44(2), 339-370.

LYONS, J. (1982), «Deixis and subjectivity: Loquor, ergo sum?», en Speech, Place, and Action: Studies in Deixis and Related Topics, Jarvella R. J. i Klein, W. (eds.), Nova York, Wiley, 101-124.

MARTINES, J. (2012), «Aproximació a les novetats lèxiques i semàntiques del Curial e Güelfa», en Estudis lingüistics i culturals sobre Curial e Güelfa, Ferrando, A. (ed.), Amsterdam, John Benjamins, 941-998. 
MARTINES, J. (2017a), «El condicional com a marcador epistèmic i evidencial en català antic: el condicional evidencial reportatiu amb verbs de dicció», Zeitschrift für Katalanistik/Revista d'Estudis Catalans, 30, 19-51.

MARTINES, J. (2017b), «L'émergence des futurs épistémiques romans. L'exemple du catalan médiéval du XIIIème siècle», en Le futur dans les langues romanes, Barnzini, L. (ed.), Berna, Peter Lang, 133-167.

MARTINES, J. (2018), «Entre la morfologia, la semàntica i la pragmàtica: el condicional evidencial reportatiu amb verbs de percepció en català antic», Anuari de Filologia. Estudis de Lingüística, 8, 259-285.

MARTINES, V. I SÁNCHEZ, E. (2014), «L'ISIC-IVITRA i el metacorpus CIMTAC. Noves aportacions a la lingüística de corpus», Estudis Romànics, 36, 423-436.

PACHECO, F. L. (1995), «Derecho valenciano, Derecho catalán y recepción del Derecho Común. Reflexiones en torno a la institución de las servidumbres prediales», Historia. Instituciones. Documentos, 22, 371-430.

Patrologia Latina Database = CHADWYCK-HEALEY, Patrologia Latina Database [en línia]. Chadwyck-Healey, 1995 [Consulta: gener 2019]. Disponible a: $<$ http://pld.chadwyck.co.uk/>.

PEIRSMAN, Y. I GEERAERTS, D. (2006), «Metonymy as a prototypical category», Cognitive Linguistics, 17, 269-316.

PujOL, J. (1998), «Micer Johan Boccacci i mossèn Joanot Martorell: presències del Decameron i de la Fiammetta al Tirant lo Blanc», Llengua E Literatura, 9, 49-100.

RAFEL, J. (1994), «Un corpus general de referència de la llengua catalana», Caplletra. Revista Internacional de Filologia, 17, 219-250.

SOLER, A. (2017), La cort napolitana d'Alfons el Magnànim: el context de Curial e Güelfa, València, Institució Alfons el Magnànim-CVEI-Institut d'Estudis Catalans.

SQUARTINI, M. (2004), «Disentangling Evidentiality and Epistemic Modality in Romance», Lingua, 114, 873-895.

SQUARTINI, M. (2012), «Evidentiality in interaction: The concessive use of the Italian Future between grammar and discourse», Journal of Pragmatics, 44, 2116-2128.

$T L F=$ CENTRE NATIONAL DE LA RECHERCHE SCIENTIFIQUE (CNRS), Trésor de la Langue Française Informatisé [en línia]. París: CNRS Éditions, 2004 [Consulta: gener 2019]. Disponible a: <http://atilf.atilf.fr/>.

TRAUGOTT, E. C. (1993), «The conflict promises to erupt into war», Berkeley Linguistics Society, 17, 348-358.

TRAUGOTT, E. C. (1997), «Subjectification and the Development of Epistemic Meaning: The Case of Promise and Threaten», en Modality in Germanic Languages, Swan, T. i Jansen Westvik, O. (eds.), Berlin-New York, Mouton de Gruyter, 185-210.

TRAUGOTT, E. C. (2012), «Pragmatics and language change», en The Cambridge Handbook of Pragmatics, Allan, K. i Jaszczolt, K. M. (eds.), Cambridge, Cambridge University Press, 549-566.

Traugott, E. C. I Dasher, R. (2002), Regularity in Semantic Change, Cambridge, Cambridge University Press.

Traugott, E. C. I Trousdale, G. (2013), Constructionalization and Constructional Changes, Oxford, Oxford University Press.

Verhagen, A. (2000), «The Girl that Promised to Become Something: An Exploration into Diachronic Subjectification in Dutch», en The Berkeley Conference on Dutch 
Linguistics 1997: the Dutch Language at the Millennium, Shannon, T. F. i Snapper, J. P. (eds.), Lanham MD, University Press of America, 197-208.

VFaraudo = FARAUDO DE SAINT-GERMAIN, Ll, Vocabulari de la Llengua Catalana Medieval de Lluís Faraudo de Saint-Germain [en línia]. Barcelona: Institut d'Estudis Catalans, (en construcció) [Consulta: gener 2019]. Disponible a: $<$ http://www.iec.cat/faraudo/default.asp\#top $>$.

VTreccani = IsTITUTO DELL'ENCICLOPEDIA ITALIANA, Vocabolario Treccani [en línia]. Roma: Instituto dell'Enciclopedia Italiana [Consulta: gener 2019]. Disponible a: $<$ http://www.treccani.it/vocabolario/>. 